Article

\title{
Probabilistic Seismic Demand Analysis of a Bridge with Unbonded, Post-Tensioned, Concrete-Filled, Fiber-Reinforced Polymer Tube Columns
}

\author{
Manisha Rai ${ }^{1}$, Mohamed A. ElGawady ${ }^{2, *(1)}$ and Adrian Rodriguez-Marek ${ }^{3}$ \\ Guidewire Cyence Risk Analytics, San Mateo, CA 94401, USA; mrai@guidewire.edu \\ Civil, Arch. and Environmental Eng. Dept., Missouri University S\&T, Rolla, MO 65401, USA \\ 3 The Charles E. Via, Jr. Department of Civil and Environmental Engineering, Virginia Tech., Blacksburg, \\ VA 24060, USA; adrianrm@vt.edu \\ * Correspondence: elgawadym@mst.edu; Tel.: +1-573-308-7358
}

Received: 17 September 2018; Accepted: 5 March 2019; Published: 18 March 2019

\begin{abstract}
Ground motions at sites close to a fault are sometimes affected by forward directivity, where the rupture energy arrives at the site in a form of a very short duration pulse. These pulses impose a heavy demand on structures located in the vicinity of the fault. In this research, a probabilistic seismic demand analysis (PSDA) for a self-centering bridge is carried out. The bridge columns consisted of unbonded, post-tensioned, concrete-filled, fiber-reinforced polymer tubes. A bridge model was developed and non-linear time history analyses were performed. Three different methodologies that used spectral accelerations to predict structural responses were used, and a time-domain approach was used for PSDA. In addition to the three approaches, a time-domain PSDA methodology was also used. The results of the PSDA from the four approaches are compared, and the advantages of using the time-domain methodology are discussed. The results of the PSDA showed that for a site located very close to the fault (6 km in this study), earthquakes having a magnitude $\left(\mathrm{M}_{\mathrm{W}}\right)$ as small as $6.5 \mathrm{can}$ be significantly hazardous because the periods of pulses generated by small magnitude earthquakes coincide with the periods of the bridge. Since small magnitude events occur with greater frequency than large magnitude events, they can have important contributions to risk.
\end{abstract}

Keywords: probabilistic seismic demand analysis; concrete bridges; failures; structural design

\section{Introduction}

Current practices in the seismic design of structures involves the determination of earthquake loads using seismic hazard analysis, which is commonly performed within the framework of probabilistic seismic hazard analysis (PSHA), and then these loads for structural design are used within the design framework dictated by building codes [1]. The output of a PSHA is mean annual rates of exceedance curves for intensity measures (IM) of ground motion. The designer then selects an acceptable level of risk by selecting a return period of the $I M$. An alternative approach is to use performance-based seismic design (PBSD), which refers to a framework that allows for structural and non-structural design decisions to be made in terms of the mean annual rate of exceedance of decision variables (DV) such as dollar value of loss, death toll due to collapse, or downtime under different seismic demands. PBSD accounts for all sources of uncertainty in computing exceedance curves for the DV. These computations involve, among other steps, the computation of the mean annual rate of exceedance of parameters that characterize structural response through engineering demand parameters (EDPs). The computation of these exceedance rates is known as probabilistic seismic demand analysis (PSDA) [1]. 
In this paper, PSDA was applied to a self-centering bridge that was affected by near-fault ground motions. This problem is of particular interest since there is a strong momentum around the world to develop self-centering bridge systems; however, the behavior of self-centering bridges under pulse-type loading has not been studied. The methodology presented in this paper uses a traditional PSHA methodology for computing structural responses for ordinary ground motions. Furthermore, the paper introduces a time-domain methodology for computing structural responses of the bridge to the pulse-like ground motions resulting from forward directivity effects.

The paper starts by presenting background information on PSDA, self-centering bridges, and near-fault ground motion. The model used for structural analysis of the bridge is then described, followed by a description of the PSDA approach adopted for this study. Results are then discussed in terms of the improvement in structural predictions brought upon by the use of the time-domain PSDA approach.

\section{Background}

Forward directivity (FD) occurs when the fault rupture propagates towards the site at a velocity nearly equal to the shear wave velocity; these effects are observed at sites that are located in the direction of rupture propagation. Ground motions affected by FD are different from those recorded far from the fault [2]. In FD ground motions, the energy from the fault rupture arrives at the near-fault site in the form of one or more large pulses, which results in a large seismic demand on a structure [3-12]. Near-fault pulse-like ground motions have both higher IM levels than non-pulse ground motions and produce higher responses for the same IM level compared to non-pulse ground motions [2,13-16].

\subsection{Pereformance-Based Seismic Design}

PSDA involves the convolution of the hazard curve for an IM with the fragility curve, which predicts structural responses through EDP in terms of the selected IM. This is expressed as:

$$
\lambda_{E D P}=\int P(E D P>x \mid \mathrm{IM})|d \lambda(\mathrm{IM})|,
$$

where the term $d \lambda$ is the slope of the mean annual rate of exceedance curve (e.g., the hazard curve) of the IM, and the term $\mathrm{P}(E D P>x \mid \mathrm{IM})$ is the conditional probability of exceeding a given EDP level for a given IM (e.g., the fragility curve).

Recently, Sehhati et al. [16] proposed a methodology to account for near-fault effects in the PSDA analysis of multi-story steel frame buildings. They showed that for multi-story structures, the EDPs resulting from ground motions having forward directivity are similar to those resulting from Gabor wavelet pulses when $0.50<\mathrm{Tp} / T_{1}<2.5$, where $T_{1}$ is the fundamental period of the structure and $\mathrm{Tp}$ is the pulse period. Within this range of periods, the structure under consideration could be analyzed using simple pulses, which significantly reduces the analysis cost and time.

\subsection{Self-Centering Bridges}

Under the prevailing capacity design concepts, correctly designed and detailed reinforced concrete (RC) structures are anticipated to exhibit an inelastic response, damage, and permanent drifts at the conclusion of ground motion excitation. These damages require expensive repairs, or even complete replacements, leading to long-term closures of highways.

Research has shown that implementing a self-centering system using an unbonded, post-tensioning, precast construction system can minimize residual displacement and damage to concrete structures as a result of seismic loads [17]. The inelastic deformations are accommodated within the connection itself where a controlled rocking motion occurs (from the opening and closing of the existing gap). Using this concept, the structural element remains elastic with limited damage [18].

A few researchers have investigated the seismic response of segmental precast post-tensioned (PPT) columns [19-21]. Tests showed that PPT segmental columns were capable of undergoing 
large nonlinear displacements without experiencing significant or sudden losses of strength. The nonlinearity resulted from the opening of the gaps between segments rather than material nonlinearity, leading to limited hysteretic energy dissipation. Furthermore, residual displacements and damages were smaller than those corresponding to typical monolithic RC columns. Increasing the post-tensioning force significantly reduced the residual displacement but led to more concrete crushing [22]. Furthermore, to minimize concrete local damage, concrete-filled, fiber-reinforced polymer (FRP) tubes (CFFT) were used. CFFTs is an emerging system for both monolithic and rocking columns $[23,24]$.

This study uses the PSDA framework recently proposed by Sehhati et al. [16] to determine the seismic demand on a self-centering concrete bridge located in the near-fault region and subjected to potential FD effects. The results from this PSDA were compared to those from more traditional approaches used to carry out the PSDA analysis for near-fault sites.

\section{Bridge Prototype and Modeling}

A bridge having general geometric characteristics similar to those used in the NCHRP Project 12-49 [25] was adopted (Figure 1). The bridge had five equal spans of $30.5 \mathrm{~m}$ each, with four intermediate bents of $9.8 \mathrm{~m}, 14.8 \mathrm{~m}, 16.4 \mathrm{~m}$, and $14.8 \mathrm{~m}$ heights, respectively. The superstructure was a cast-in-place concrete box girder with three cells. The RC columns of the bridge in the NCHRP Project 12-49 had a diameter of $1.17 \mathrm{~m}$. For this study, these columns were replaced by precast post-tensioned concrete-filled fiber tube (PPT-CFFT) piers which have self-centering capabilities [26-28]. In order to come up with PPT-CFFT columns comparable in strength and stiffness to those in the original design, the dimensions of the new column were selected identical to those of the original columns (Figure 2). The chosen FRP had an elastic modulus and tensile strength of $1.5 \mathrm{GPa}$ and $234 \mathrm{MPa}$, respectively, in the hoop direction. The FRP tube thickness was taken as $15.4 \mathrm{~mm}$. Grade 160 unbonded post-tensioned steel bars were used. An initial post-tensioning force corresponding to a value of $45 \%$ of concrete compressive strength $\left(f^{\prime}\right)$ was found to give an initial yield moment and ultimate moment capacity very similar to that of the RC section in the original design. Initial steel stress of $60 \%$ of the rebar yield stress was selected, based on the recommendation in the literature $[27,28]$.

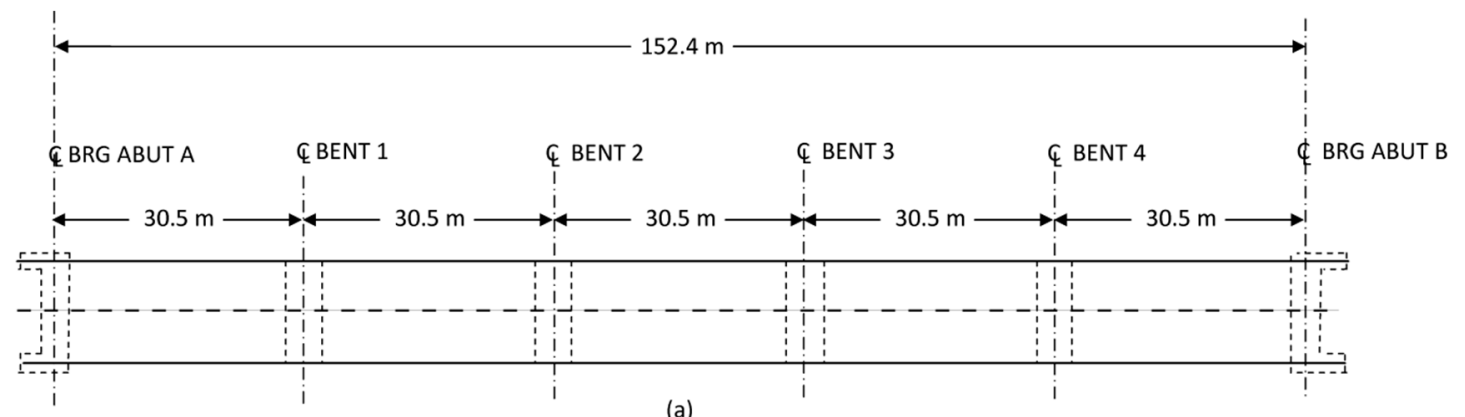

(a)

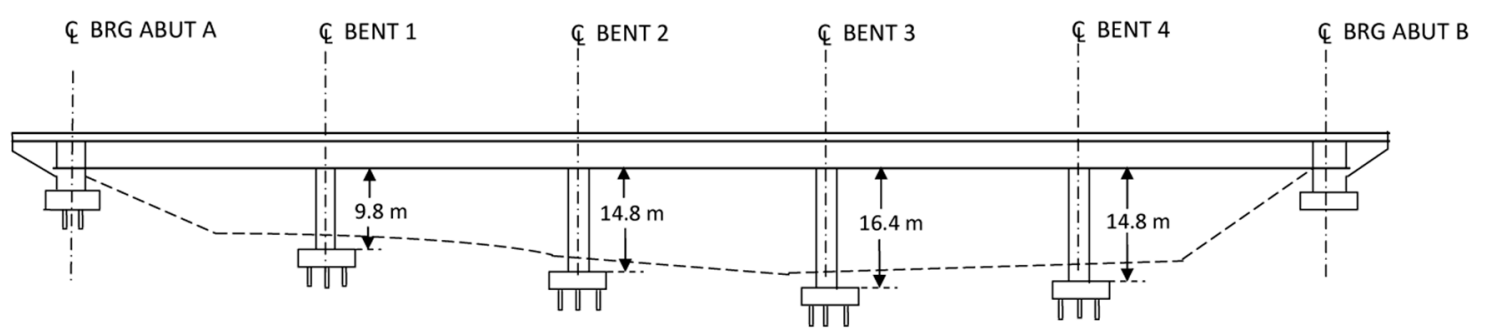

(b)

Figure 1. Bridge structure. (a) Plan and (b) Elevation (reproduced from Zhu et al. [27]). 


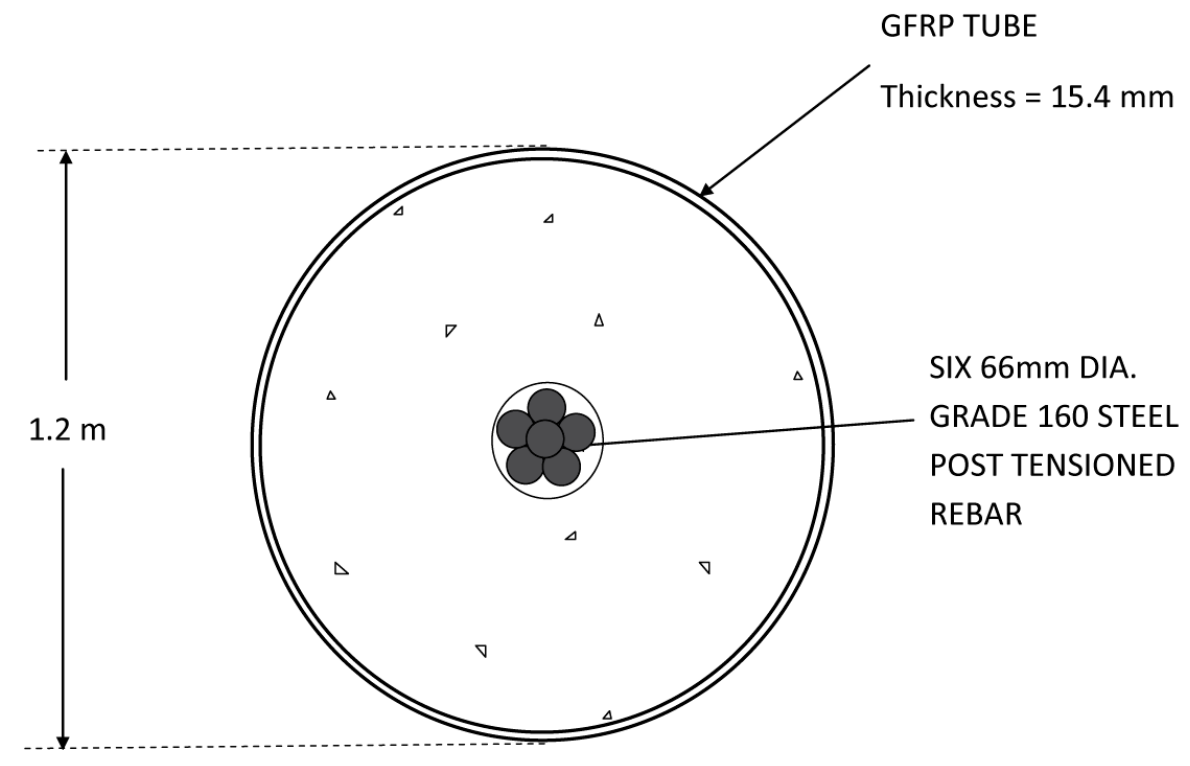

Figure 2. Column cross-section.

A three-dimensional spine bridge model was developed in SAP2000 (Figure 3a). The bridge superstructure was modeled using elastic beam elements passing through the centroid of the superstructure. A cross girder at each bent was modeled using beam elements located at the centroid of the box girder (Figure 3b). A rigid beam element was used to connect the top of the column to the cross girder [29]. The columns were modeled using beam elements located at the geometric center of each column. Rigid moment connections were used between each column and its foundation, as well as between each column and the corresponding link that was connected to the superstructure. Plastic hinges were selected at the top and bottom ends of each column (Figure 4). The girder had a dead load of $60 \mathrm{kN} / \mathrm{m}$. Additional dead loads included two-end diaphragms, $525 \mathrm{kN}$ each, five intermediate diaphragms, $68 \mathrm{kN}$ each, and four intermediate cross beams of $454 \mathrm{kN}$.

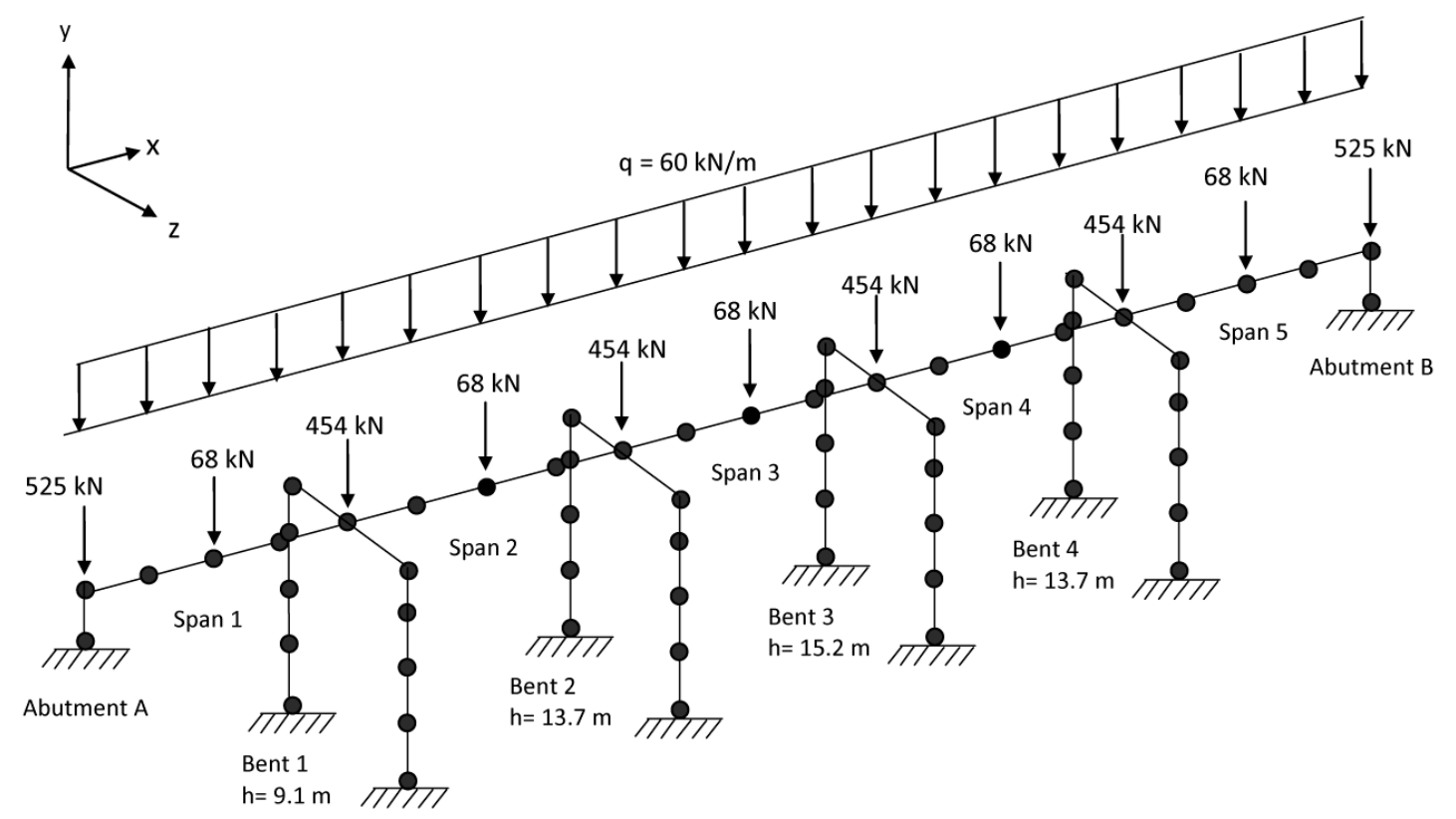

(a)

Figure 3. Cont. 


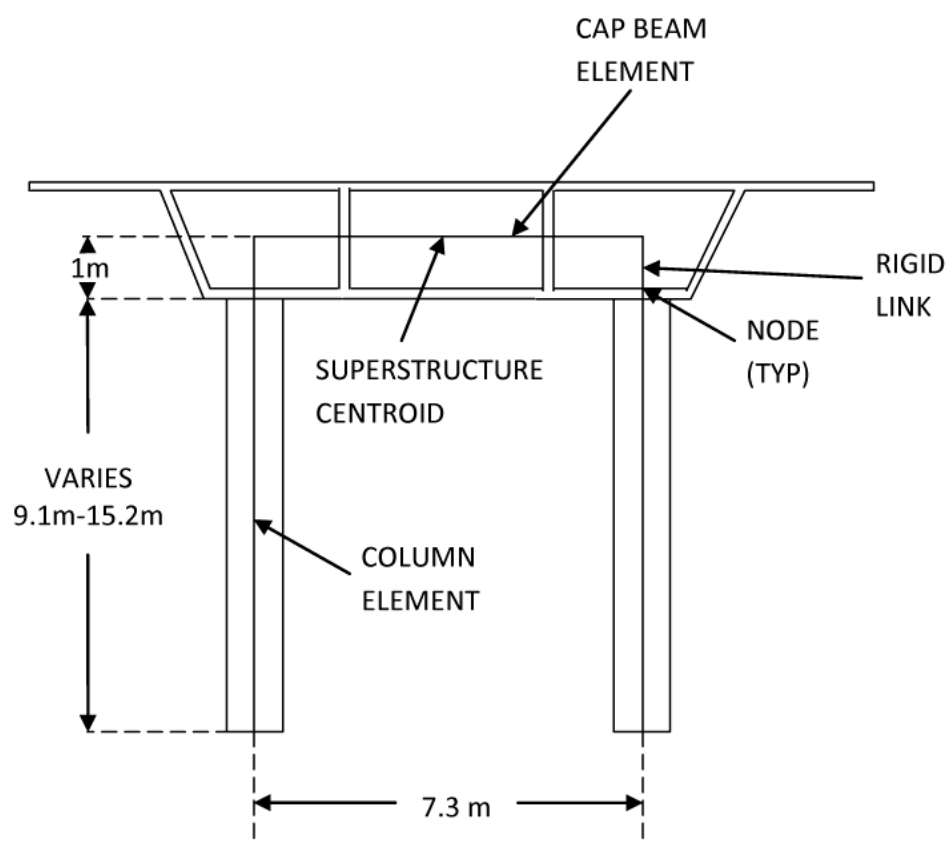

(b)

Figure 3. Bridge model: (a) entire bridge structure and (b) pier frame (reproduced from Zhu et al. [27]).

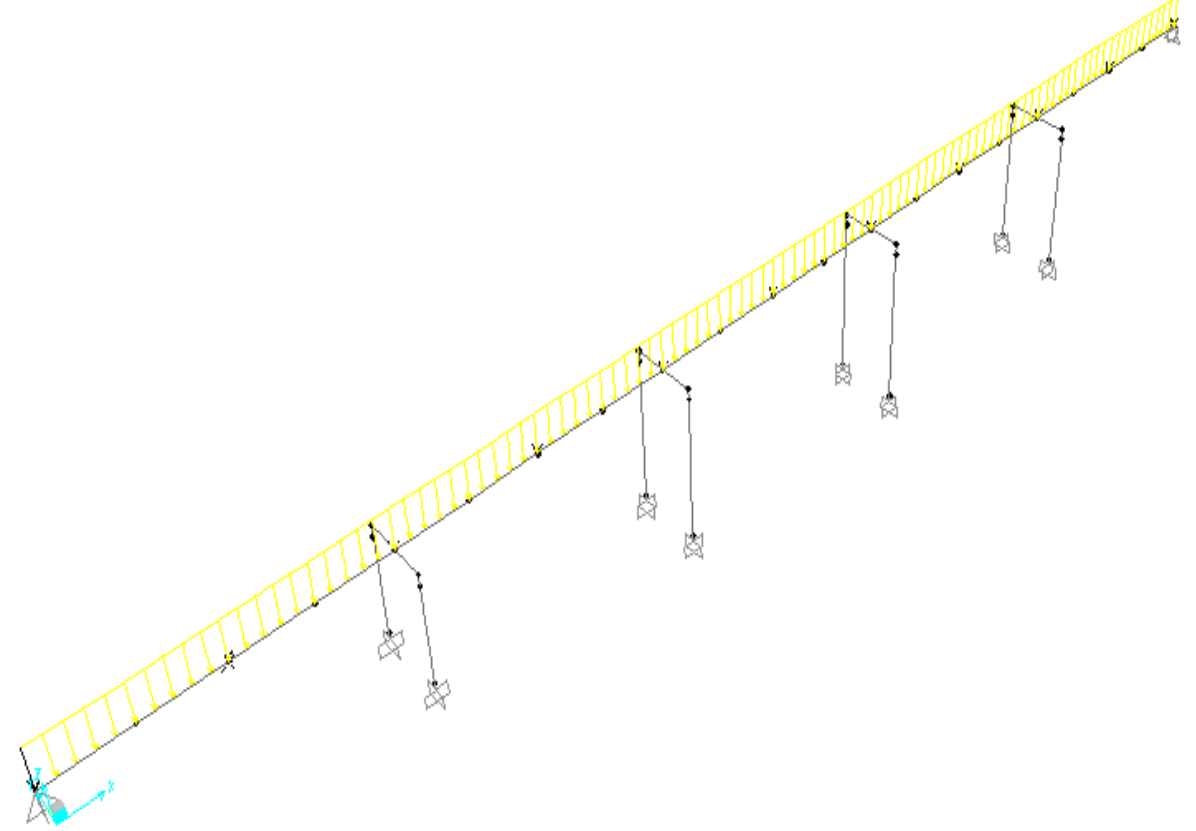

Figure 4. SAP2000 model of the bridge.

The moment curvature relation along with the axial-force-moment interaction diagram was used to define the plastic hinges. Moment curvature of an unbonded, post-tensioned column is inherently different from conventional RC columns. Hewes and Priestley [30] used an iterative model to calculate the moment-curvature and backbone relationships for an unbonded, post-tensioned column. A similar procedure was used in this paper to determine the moment-curvature of the unbounded, post-tensioned column. The unconfined concrete compressive strength was considered as $27.6 \mathrm{MPa}$. The confined concrete was modeled using the Samaan et al. [31] model. Grade 160 steel rebar was used for the post-tensioning tendons. The steel had an elastic modulus of 204,774 MPa, a yield stress of $874 \mathrm{MPa}$, an ultimate stress of $1109 \mathrm{MPa}$, and an ultimate strain of $10 \%$. 
The moment curvature analysis was carried out for a given post-tensioning force and different values of applied axial loads. Since there was no clear yielding point for unbonded, post-tensioned columns, a bilinear idealization was used using equal energy concepts. The onset of the post-elastic point was considered as the yielding point. Finally, an axial load-moment interaction diagram was developed and was used as an input in SAP2000 (Figure 5).

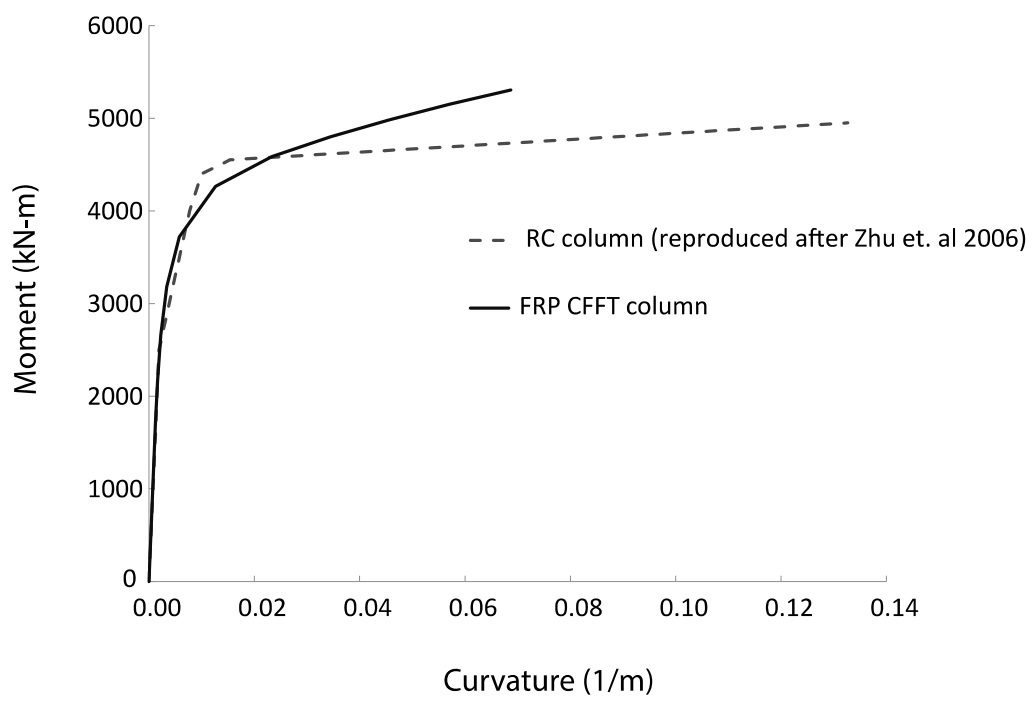

Figure 5. A comparison of the moment-curvature plot of a concrete-filled, fiber-reinforced polymer tube (FRP-CFFT) column (at an initial concrete compression stress of $45 \% \mathrm{f}_{\mathrm{c}}^{\prime}$ ) with a reinforced concrete (RC) column reproduced from Zhu et al. [27].

In order to calibrate the nonlinear behavior of the FRP-CFFT columns, pushover analyses were performed using SAP 2000 on columns identical to those used in the bridge model. The columns had heights of $9.1 \mathrm{~m}, 13.7 \mathrm{~m}$, and $15.2 \mathrm{~m}$. Each column was subjected to an initial axial load value of $3118 \mathrm{kN}$. The pushover curves were calculated using the Hewes and Priestley [28] model (Figure 6). The calibrated model of the bridge was then used for the non-linear time history analyses explained later in this paper.

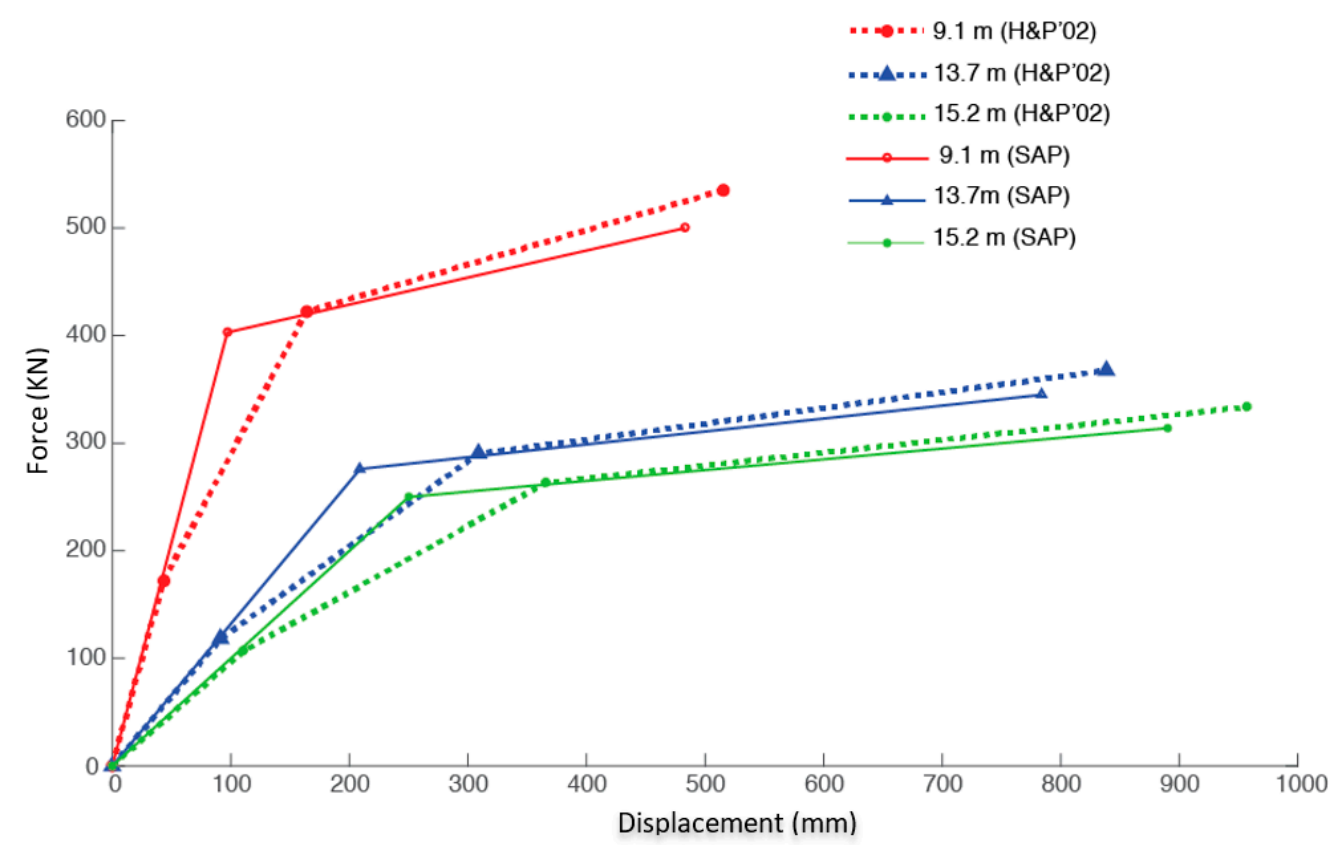

Figure 6. Comparison of pushover curves from SAP2000 and from Hewes and Priestly [28] model for the three columns after calibration. 


\section{Ground Motions and Fault Geometry}

For the non-linear time history analyses of the bridge, the ground motions were extracted from a database compiled by Sehhati et al. (2011) that included a set of 27 FD and 27 non-forward directivity (NFD) ground motions. Each ground motion was recorded for earthquakes with moment magnitudes $\left(\mathrm{M}_{\mathrm{W}}\right)$ greater than 6.5 and at a source-to-site distance (R) less than $20 \mathrm{~km}$. Only the fault-normal components of these records were used and applied to the bridge in the weak/transverse direction. It was assumed that the weak axis of the bridge was perpendicular to the fault. The maximum bridge drift at the top of the bridge column was selected as the EDP.

A hypothetical vertical strike-slip fault of $240 \mathrm{~km}$ length was considered. For simplicity of calculation, it was assumed that the fault was a straight line and the seismicity rate was 1 . The earthquake magnitude distribution was assumed to follow a bounded Gutenberg-Richter recurrence law with a beta value of 1.84 (or $b=0.8$ ) and with bounding magnitudes of 5.0 and 8.0. In the Gutenberg-Richter law, the probability of exceedance of any given magnitude decreases exponentially with the magnitude. The longitudinal direction of the bridge was assumed to be parallel to the fault longitudinal axis, as shown in Figure 7. Four different fault-site distances $(6,11,16$, and $21 \mathrm{~km})$ were considered in the analyses to investigate the effects of source-to-site distance on the analysis. For each location of the bridge, four different approaches were used for the PSDA.

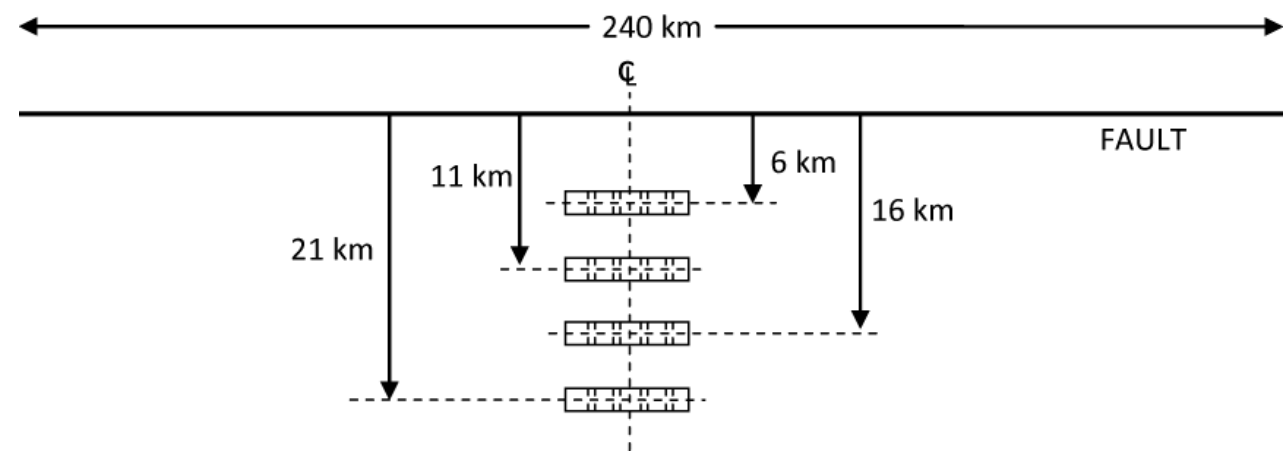

Figure 7. Fault geometry and bridge locations used in the study.

\section{Probabilistic Seismic Demand Analysis (PSDA) Approaches}

The PSDA computations used the annual rate of exceedance of one or more IMs to obtain the annual rate of exceedance of an EDP $\left(\lambda_{E D P}\right)$. Four different approaches to compute PSDA for the bridge were used during the course of this study. These approaches can be split into two main broad groups, namely, the conventional approach and the time-domain approach. In the ensuing, each of these approaches are discussed in detail.

\subsection{Conventional PSDA Approach}

The conventional PSDA is described by Equation (1). This equation requires the definition of the hazard curve for $S a$, and the probability of exceeding an EDP value for a given $S a$. In this study, three different approaches to obtain these two functions were applied:

I. The traditional PSDA approach, in which the near-fault directivity effects were purposely ignored. This analysis was conducted as a baseline case for comparison with cases in which near-fault effects were accounted for. The Abrahamson and Silva [32] ground motion prediction equation (GMPE) was used in this study for predicting the $S a$. Note that while this GMPE has been largely superseded by more recent GMPEs, the choice of GMPE does not affect the comparison exercise conducted in this paper. The EDP was formulated using a statistical relationship between EDP and IM, obtained using results of non-linear time history analyses of the bridge for near-fault and ordinary (i.e., without directivity effects) ground motions. 
II. The broadband PSDA approach, in which near-fault directivity effects were accounted for by using a modified GMPE. This study used the modified attenuation models developed by Somerville et al. [2] and Abrahamson [33]. This approach was called the Broadband approach because the selected GMPEs amplified the $S a$ predictions for near-fault sites in a wide range (i.e., broadband) of periods. The Broadband approach accounted for the effect of near-fault pulses on the IM observed at the site, but it ignored the effect of pulses on EDP for a given IM level.

III. The enhanced broadband approach in which the same GMPE as in the broadband case was used, but the effects of near-fault directivity on EDP were also accounted for. The enhanced broadband approach used different predictive equations for EDP (as a function of IM) for cases when directivity effects were observed and when they were not observed.

\subsection{Time-Domain PSDA Approach}

The time-domain approach proposed by Sehhati et al. [16] extends the enhanced broadband approach by directly using the results of time-domain analyses along with a vector of IMs. The essence of this approach is that for cases when ground motions have pulses, the EDP is predicted using simplified wavelet pulses instead of a correlation with IM. The parameters that characterize the pulse motions are the amplitude and period of the pulse. For this purpose, ground motion scenarios were divided into four cases: non-near-source (non-NS), near-source no pulse (NS-NP), near-source pulse-dominant (NS-P-in), and near-source pulse-non-dominant (NS-P-out). The near-source pulse-dominant case refers to the case when the pulse in the near-source ground motion drives the structural response. This occurs when the period of pulse in the ground motion is within a certain range of the structural period [16], thus, the EDP of the structure can be predicted using a vector IM (e.g., pulse amplitude, $A p$, and pulse period, $T p$ ) and time domain analyses using wavelets. The near-source pulse-non-dominant case refers to scenarios where directivity effects are observed at the site, but the period of the resultant pulse is very different from the period of the structure. In these scenarios, an EDP-IM relationship for forward-directivity ground motions is used for EDP prediction.

\section{Models Required for PSDA}

The PSDA methodology that was developed by Sehhati et al. [16] was used in this study. The broadband, enhanced broadband, and time-domain approaches divided the hazard scenarios into forward directivity and non-forward directivity cases; hence, the probability of observing forward directivity ground motion at a given site, due to a given fault scenario, is required to carry out the PSDA. The model proposed by Iervolino and Cornell [34] was used to predict the probability of observing forward directivity at a given site from a given fault scenario.

To carry out the time-domain PSDA, it was required to determine the pulse amplitude $(A p)$ and pulse period $(T p)$ at a given site. This study predicted pulse amplitude as a function of peak ground velocity (PGV) from the Bray and Rodriguez-Marek [35] model for distances less than $20 \mathrm{~km}$ from the fault. For distances greater than $60 \mathrm{~km}$, a model developed by Abrahamson and Silva [32] was used to predict PGV, and subsequently, pulse amplitudes. For intermediate distances (i.e., between 20 to $60 \mathrm{~km}$ ), a taper was used to transition between the two models [16]. The Baker [36] model was used to predict the pulse period, $T p$.

\subsection{Engineering Demand Parameter-Intensity Measure (EDP-IM) Relationship for Forward Directivity (FD)} and Non-Forward Directivity (NFD) Ground Motions

The $E D P-S_{a}$ relationship for both pulse-like and non-pulse-like ground motion was needed for the enhanced broadband approach. The maximum column drift angle resulting from non-linear time history analyses of the bridge structure for FD and NFD ground motions were plotted in Figure 8 as a function of the spectral acceleration of the input ground motion at the fundamental period of the bridge, $S_{a}\left(T_{1}\right)$. A power-law relationship was used and a least-square regression was employed to fit 
a curve that represented the median of the maximum column drift for a given $S_{a}$. Equation (2) shows the developed relationship:

$$
\text { Max.Column Drift }(\%)==\left\{\begin{array}{c}
1.0749\left(S_{a}\left(T_{1}\right)\right)^{0.76}, \text { for FD } \\
0.8597\left(S_{a}\left(T_{1}\right)\right)^{0.69}, \text { for NFD }
\end{array},\right.
$$

with standard deviations of the residuals, $\sigma_{l n}$, valued at 0.27 and 0.25 for FD and NFD, respectively. As shown in Figure 8, the medians of the maximum drifts for FD ground motions were higher than those of NFD ground motions for a given $S_{a}$. This occurred because pulses induced higher nonlinearities in the bridge, resulting in a higher structural demand.

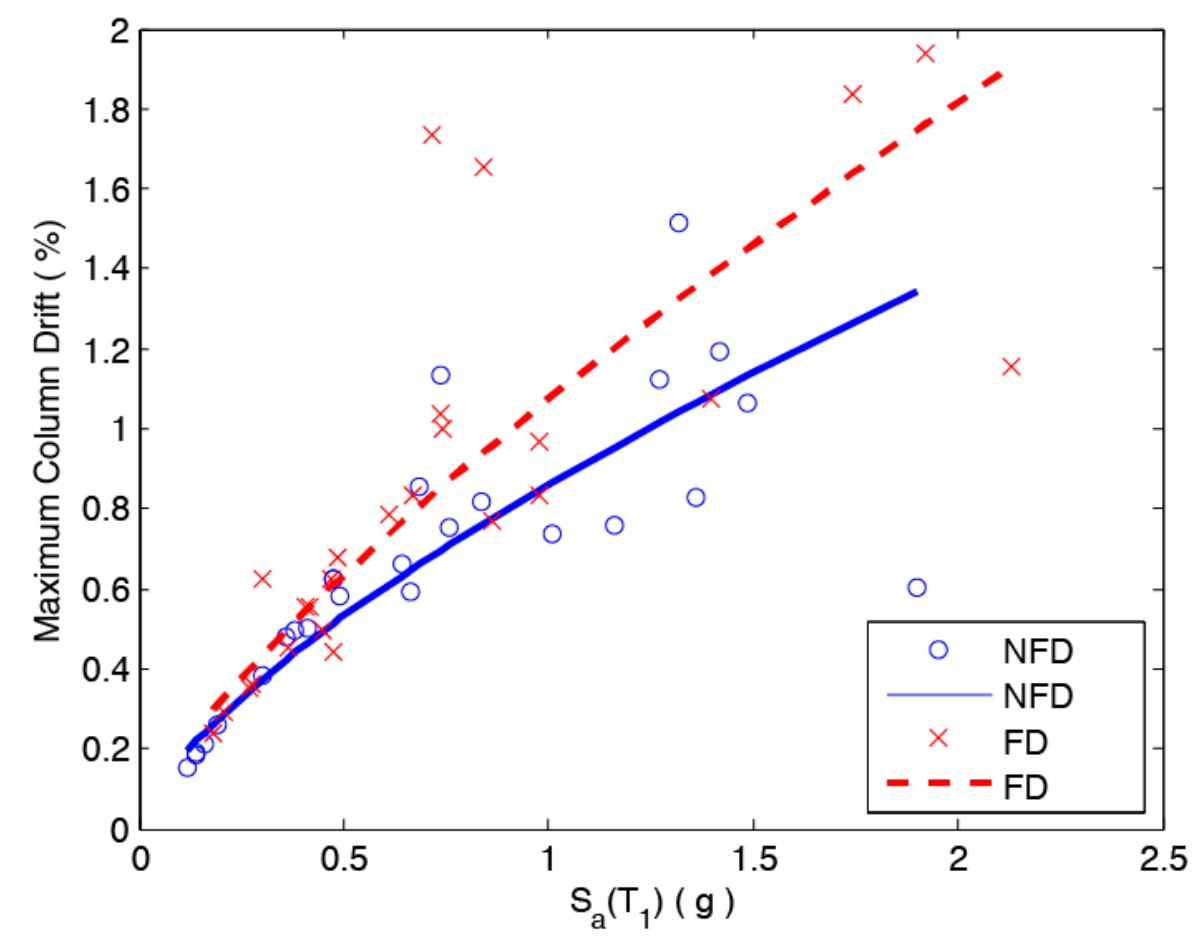

Figure 8. Plots of bridge responses to forward directivity (FD) and non-forward directivity (NFD) ground motions.

\subsection{EDP Versus Pulse Parameter Relationship for Simplified Pulses}

A relationship between $E D P$ and pulse parameters $\left(A_{p}, T_{p}\right)$ was required for the time-domain approach. Sehhati et al. [16] showed that for cases when ground motion pulses dominate structural response, a simplified wavelet pulse could be used to capture the response of a structure to the pulse motions. Similarly, in this study Gabor pulses were used to capture the response of the bridge structure to pulse-like motions. The velocity time history of a Gabor pulse is given by the following equation [36]:

$$
V(t)=\left\{\begin{array}{cc}
A \frac{1}{2}\left[1+\cos \left(\frac{2 \pi f_{p}}{\gamma}\left(t-t_{0}\right)\right)\right] \cos \left[2 \pi f_{p}\left(t-t_{0}\right)+v\right], & t_{0}-\frac{\gamma}{2 f_{p}} \leq t \leq t_{o}+\frac{\gamma}{2 f_{p}} \\
0, & \text { Otherwise }
\end{array}\right.
$$

where, $A$ is proportional to the amplitude of the wavelet, $f_{p}$ is the prevailing frequency of the signal, $v$ is the phase angle (i.e., $v=0$ and $v= \pm \pi / 2$, defining symmetric and anti-symmetric signals, respectively), $\gamma$ defines the oscillatory character of the signal, and $t_{o}$ is the time of the envelope's peak. In this study, only $v=0$ had been considered, for simplicity. Hence, the only parameters that were required to define the Gabor wavelet pulse were $A, f_{p}$, and $\gamma$. The Baker [36] procedure was used to extract the pulse from FD ground motion, and based on the number of peaks and troughs of the extracted pulses, the parameter $\gamma$ was set as 3 . 
Time history analyses of the bridge model were carried out under the effects of different Gabor pulses and forward-directivity ground motions. Figure 9 shows a ratio of computed EDP values (in this case, the maximum column drift angle) for the recorded forward-directivity ground motions and for equivalent pulses. Sehhati et al. [16] observed that for multi-degree-of-freedom structures, the responses to the FD ground motions were equal to the responses to equivalent simplified pulses (i.e., ratio $=1$ ) when $0.5<T_{p} / T_{1}<2.5$ for multi-degree-of-freedom structures. For the bridge under study, this was the case for $T_{p} / T_{1}<1.75$. For the lower limit on $T_{p} / T_{1}$, the lower limit of 0.5 was adopted from Sehhati et al. [16]. Nonlinear time-history analyses were performed in SAP2000 using simplified Gabor pulses for this range of pulse period and for a range of pulse amplitudes $\left(15<A_{p}\left(\frac{\mathrm{cm}}{\mathrm{s}}\right)<60\right)$. Maximum bridge drifts and base shear forces were monitored for all pulses; however, only the former was considered as the EDP. A genetic algorithm (Schmidt and Lipson, 2009) was used to perform a symbolic regression to find the functional form for the maximum drift. The surface (Figure 10) for the maximum column drift had the following functional form:

$$
\operatorname{Max} \operatorname{Drift}(\%)=\frac{5.03073+A_{p}}{\left(\frac{127.58}{\sin \left(0.0602+T_{p}\right)}-175.35 \cos \left(T_{p}\right)\right)}
$$

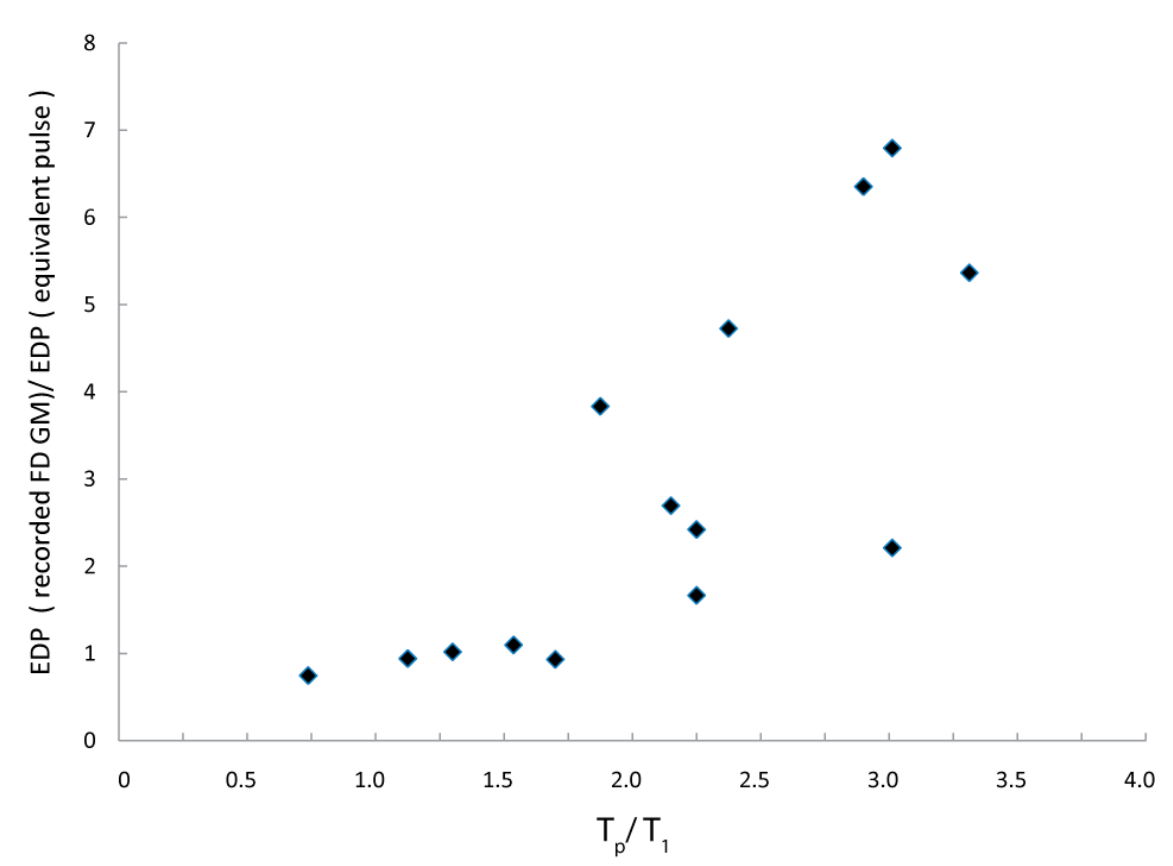

Figure 9. Plot showing the ratios of EDP computed for recorded ground motions to those computed using equivalent pulses, plotted against $T_{p} / T_{1}$ 


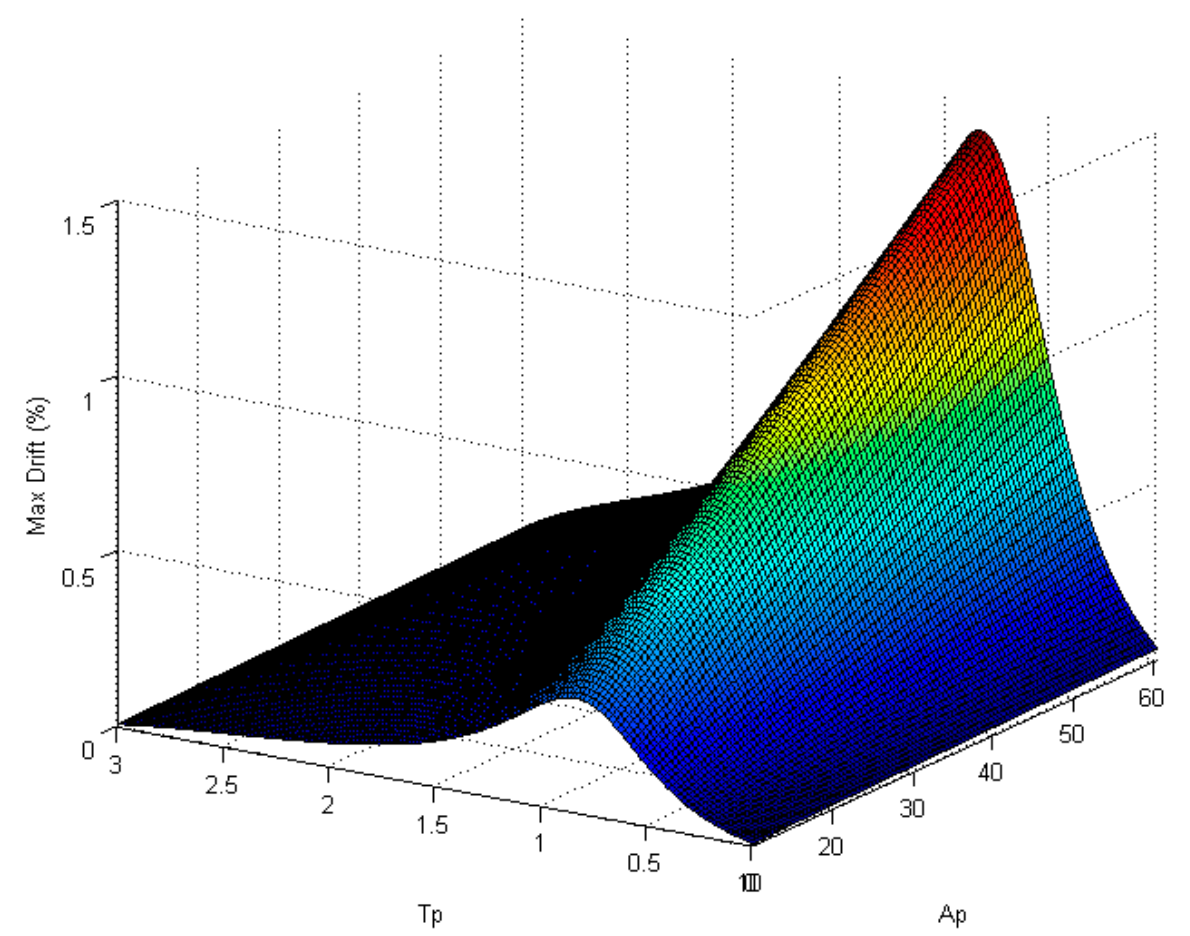

Figure 10. The EDP response surface of the bridge to simplified Gabor pulses.

\section{Results and Discussion}

The results of the PSDA for four different site locations at $6 \mathrm{~km}, 11 \mathrm{~km}, 16 \mathrm{~km}$, and $21 \mathrm{~km}$ from the fault are shown in Figure 11. The results of the enhanced broadband approach and the individual contributions from its two components, namely the pulse and non-pulse motions, are shown. Note that the probability of exceedance $\left(\lambda_{E D P}\right)$ of the non-pulse component was higher than those of the pulse component for small drift angles. However, $\lambda_{E D P}$ for the non-pulse component decreased with increasing drift angles. The reason for this variation was as follows. Lower values of drift angle could be exceeded with a high probability with lower magnitude ground motions (which occur much more frequently compared to larger magnitude ground motions). The probability that a lower magnitude earthquake will be in the form of a pulse was low. Hence, the overall probability that a smaller value of drift angle was exceeded due to a pulse component also decreased. It is worth noting that the probability of having a pulse depends on the distance between the point on the fault closest to the site and the epicenter (R), the length of rupture (S), and the angle between the strike of the fault and the line joining the epicenter to the site ( $\theta$ or theta). Lower magnitude earthquakes have smaller median fault rupture lengths; hence, they have a lower probability to be in the form of a pulse. High values of drift angle would be exceeded only with larger magnitude earthquakes that have a higher probability of having a pulse. However, such high magnitude ground motions have a lower probability of occurrence, resulting in a lower overall probability that a large drift angle is exceeded as a result of a pulse or non-pulse component.

Figure 12 shows a comparison of the probability of exceedance calculated using all four PSDA methodologies. For the site at $6 \mathrm{~km}$ (Figure 12a), all the methods yielded similar results for drift angles smaller than $0.5 \%$. Beyond that, the time-domain PSDA yielded higher values of $\lambda_{E D P}$ compared to the other three methodologies. This was because the time-domain approach captured resonance in a better way (by using $A p$ and $T p$ as intensity measures) as compared to other methodologies and was, thus, able to better capture non-linearity at higher drift levels. In addition, beyond a drift angle of about $0.5 \%$, the enhanced broadband PSDA yielded higher values of $\lambda_{E D P}$ compared to the traditional and broadband PSDA methodologies. This happened because at higher drift levels, a major contribution to EDP exceedances came from the pulse-like component that was only captured 
by the enhanced broadband approach. This implied that it was important to capture the differences in structural responses to non-pulse-like and pulse-like motions (Figure 8). At progressively larger distances from the fault (Figure 12b-d), trends similar to those discussed for the site at $6 \mathrm{~km}$ were observed. However, the probability of exceeding a particular drift angle became smaller compared to those of a site at $6 \mathrm{~km}$. Also, with increasing the distance between the epicenter and the site, the difference in the probability of exceedance calculated using the new PSDA and enhanced broadband kept decreasing, indicating the reduction in contribution of pulse-in components at this distance.
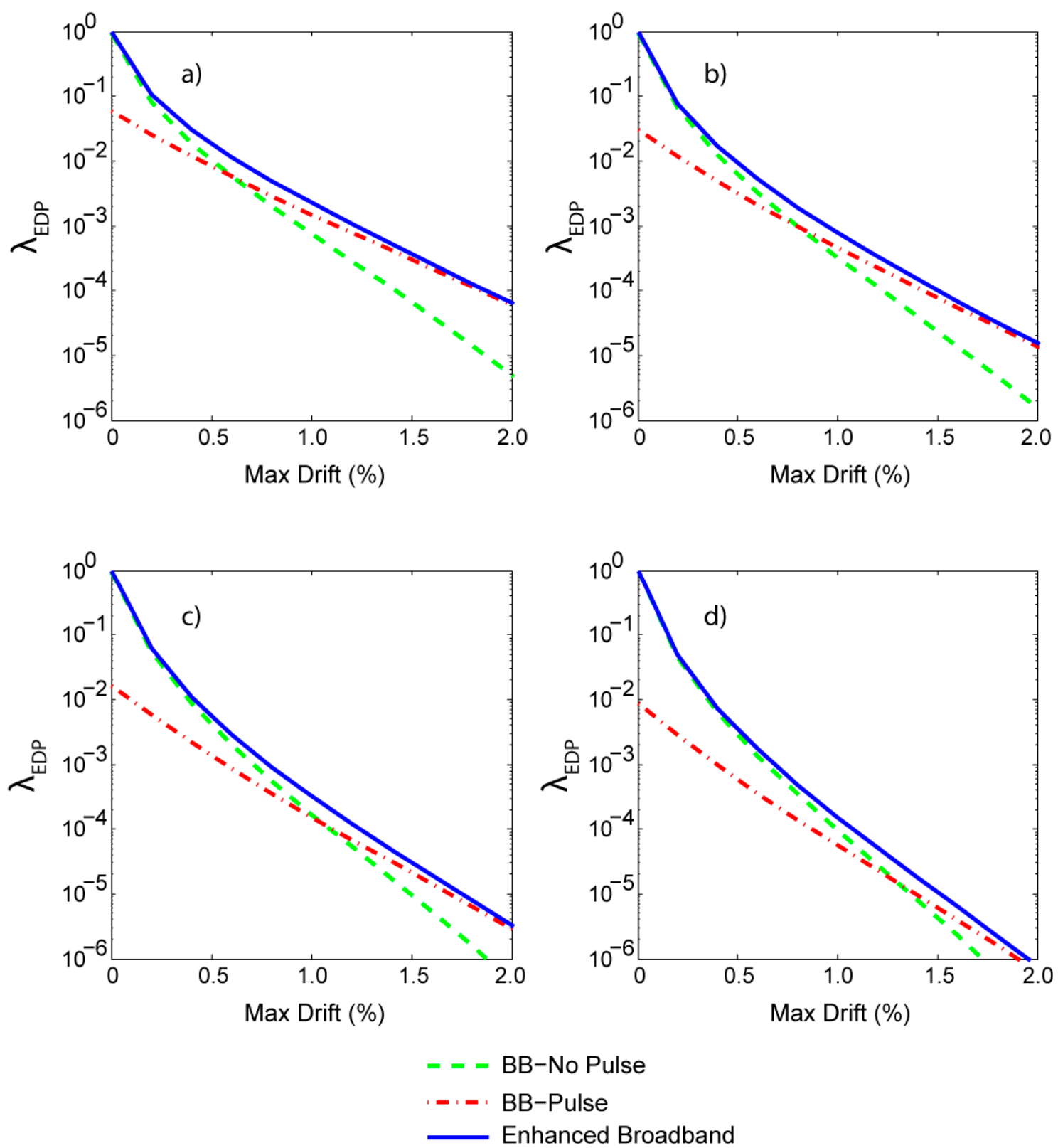

Figure 11. Rate of exceedance of drift vs. maximum drifts from the enhanced broadband approach, and the individual contributions of pulse and non-pulse motions are shown for sites located at a distance of (a) $6 \mathrm{~m},(\mathbf{b}) 11 \mathrm{~km},(\mathbf{c}) 16 \mathrm{~km}$, and (d) $21 \mathrm{~km}$ from the fault. 

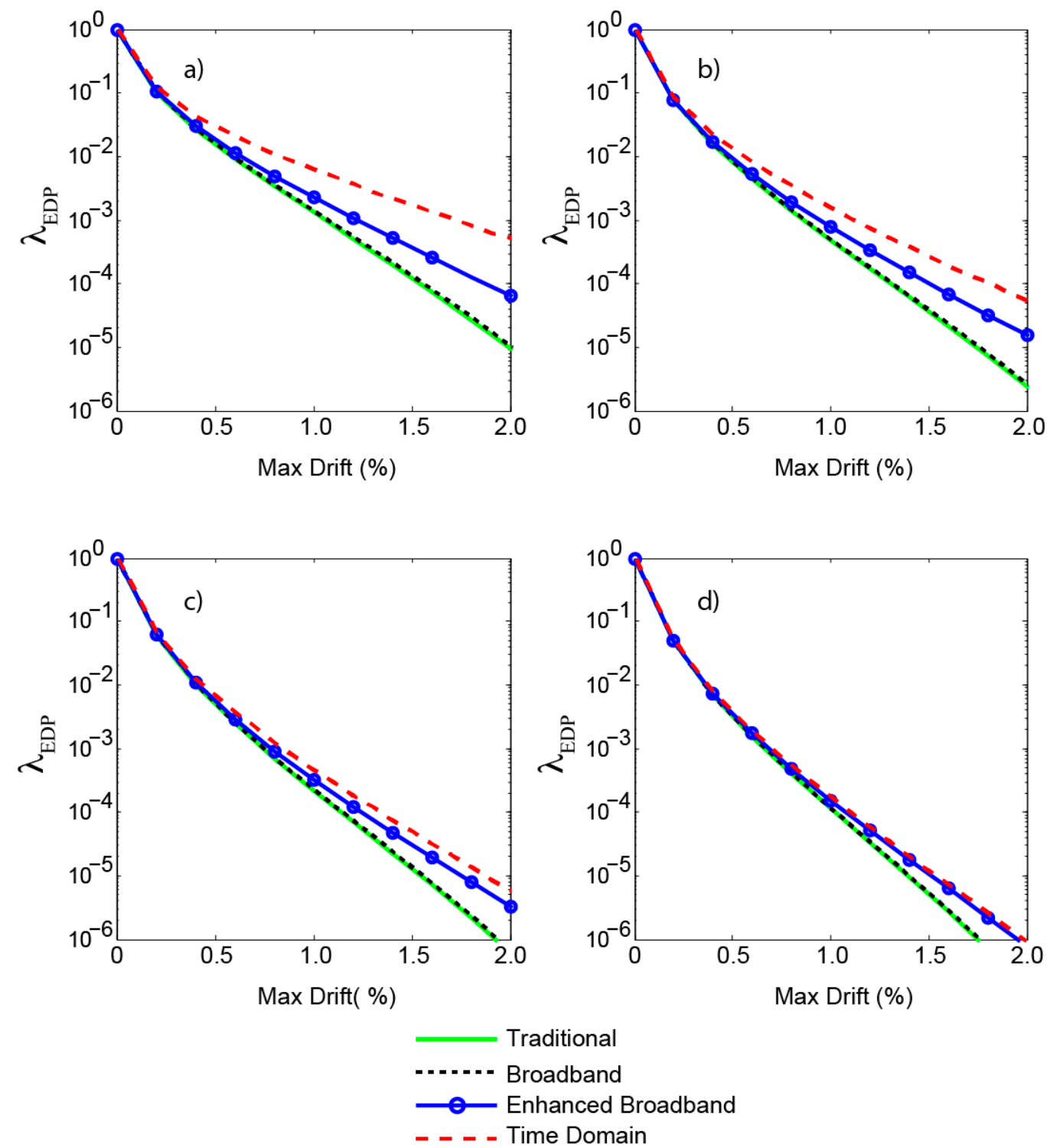

Figure 12. Rate of exceedance of drift vs. maximum drifts from the four methods (traditional, broadband, enhanced broadband and time-domain method) are shown for sites located at a distance of (a) $6 \mathrm{~m},(\mathbf{b}) 11 \mathrm{~km},(\mathbf{c}) 16 \mathrm{~km}$, and (d) $21 \mathrm{~km}$ from the fault.

Figure 13 shows the results of the proposed time-domain PSDA. The contributions of four different contributors to total demand are also shown separately ((non-NS), (NS-NP), (NS-P-in), and (NS-P-out)). As in the case of Figure 9, for smaller drift angles, the NS-NP component had the highest probability of exceedance. For higher drift angles, most of the contribution to the hazard was coming from the NS-P-in scenario, pointing to the importance of such scenarios in the hazard calculations. As the distance to the fault increased, the probability of exceeding a given drift angle decreased overall.

Figure 14 shows distance-magnitude deaggregation plots for a drift angle of $1 \%$ (which was an arbitrarily selected value for demonstration purposes). Figure 14a shows the distance-magnitude deaggregation plots for a site located at a distance of $6 \mathrm{~km}$ from the fault. Contributions from different component of the New PSDA are shown. As expected, the main contribution to the hazard came from the near-source scenario. The NS-P-in component represented about $58 \%$ of total hazard, which was the highest contribution to the hazard. The next highest contributor to the total hazard was the NS-P-out component that represented $24 \%$ of the total hazard. The NS-NP contributed $18 \%$ to the total hazard, making it the third highest contributor. The contribution from Non-NS was insignificant in 
this case, and it represented $0.0 \%$ of the total hazard. The non-near source scenarios were the ones with source-to-site distances greater than $60 \mathrm{~km}$. Given the length and the location of the fault, and the location of the site, any fault rupture that was at a distance greater than $60 \mathrm{~km}$ from the site would have a small fault rupture length, and would therefore result from a smaller magnitude earthquake. Since small magnitude earthquakes at a large distance would not be able to drive the drift of the bridge more than $1 \%$, no contributions from the non-near source scenario to the total hazard are seen.
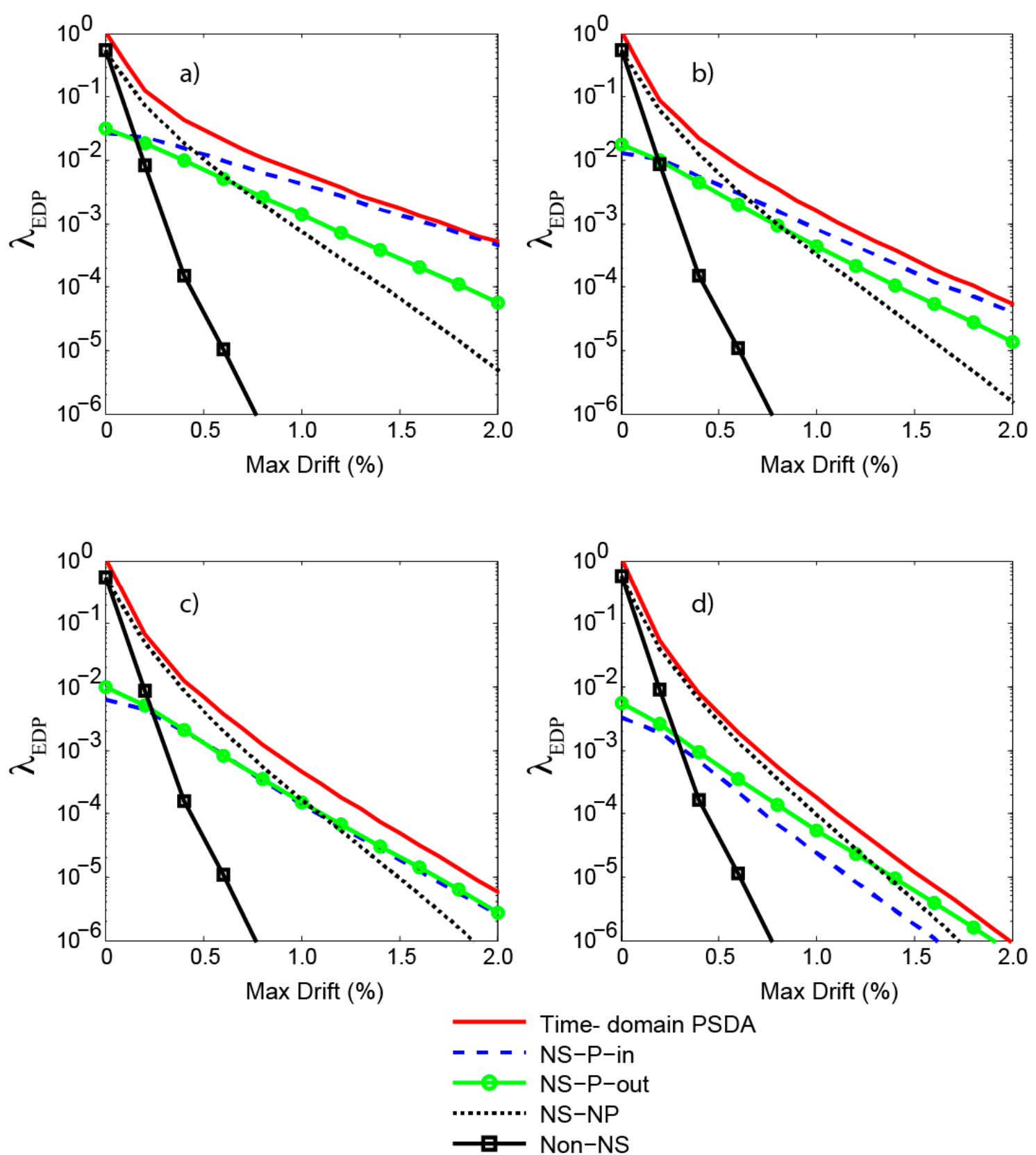

Figure 13. Rate of exceedance of drift vs. maximum drifts from the time-domain probabilistic seismic demand analysis (PSDA), and contributions from different components of the time-domain procedure are shown for sites located at a distance of (a) $6 \mathrm{~m},(\mathbf{b}) 11 \mathrm{~km},(\mathbf{c}) 16 \mathrm{~km}$, and (d) $21 \mathrm{~km}$ from the fault. The labels for the components are: NS-P-in-Near-source pulse motions with pulses dominant; NS-P-out - near-source pulse motions with non-dominant pulses; NS-NP — near-source motions without pulses; and Non-NS-non-near source motions. 

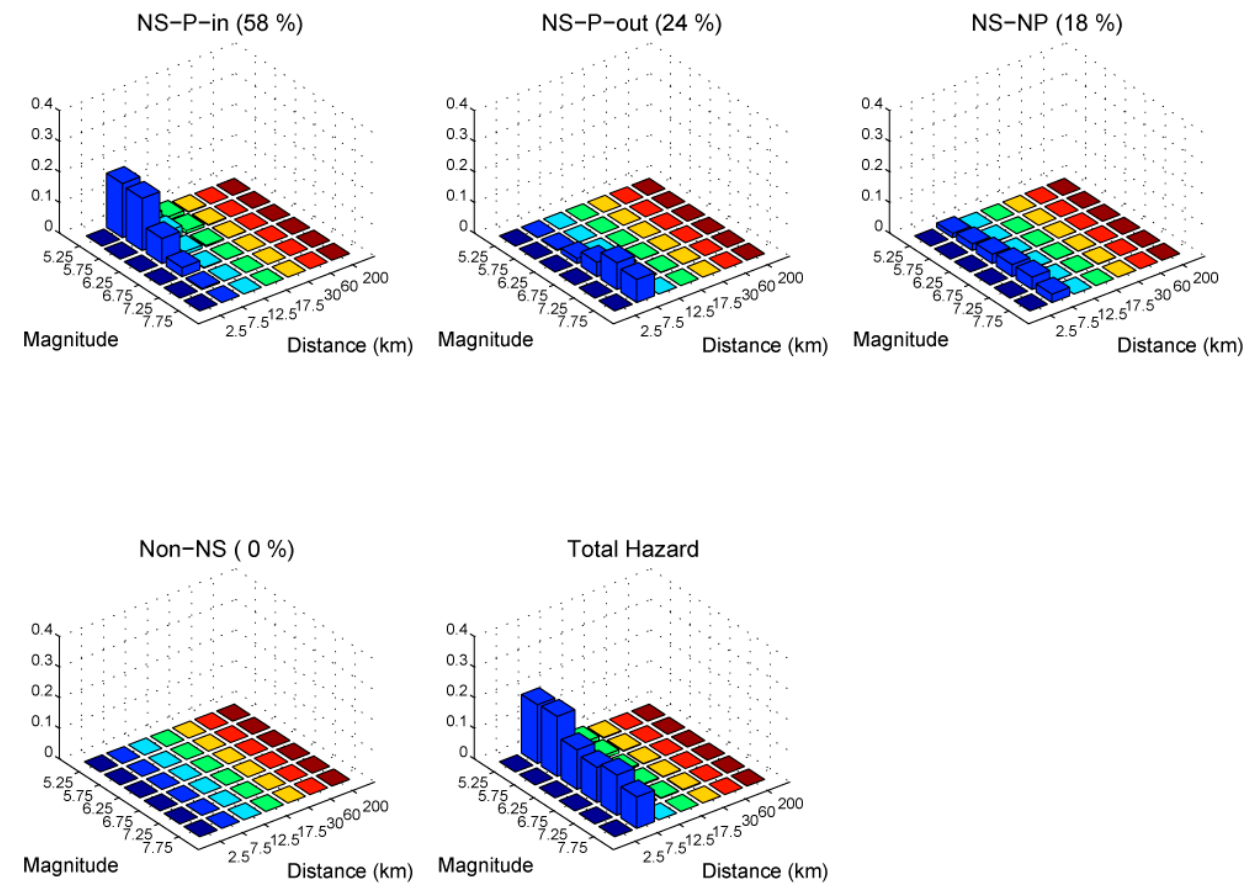

(a)

NS-P-in (46 \%)

NS-P-out (26 \%) NS-NP (28\%)
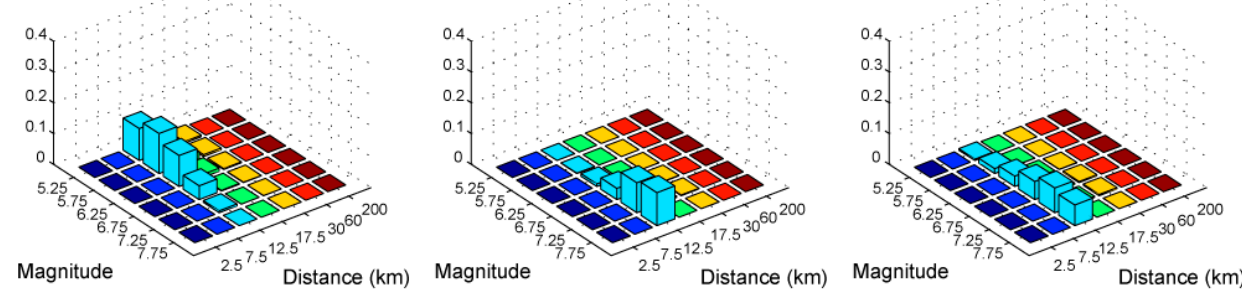

Non-NS ( $0 \%)$

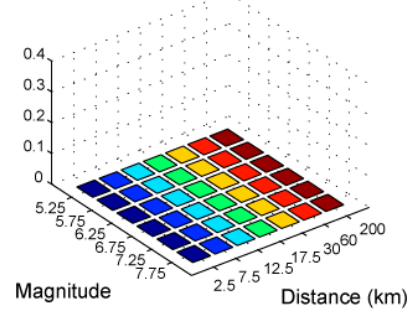

Total Hazard

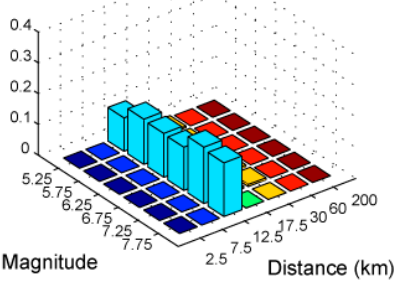

(b)

Figure 14. Cont. 
NS-P-in (28 \%)

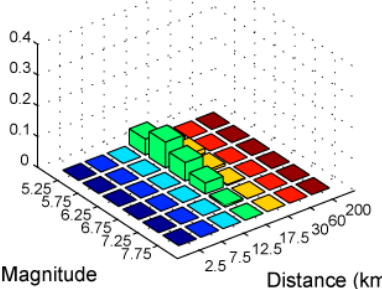

Magnitude
NS-P-out (28 \%)

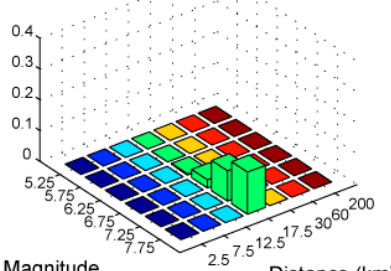

Distance (km)
NS-NP (45 \%)

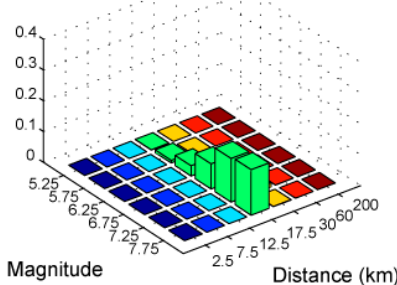

Non-NS ( $0 \%)$

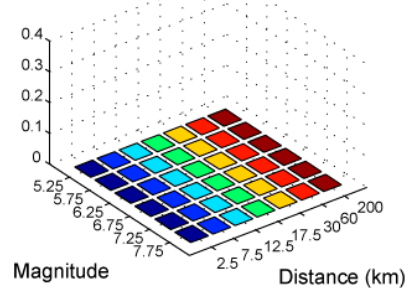

Magnitude
Distance (km)

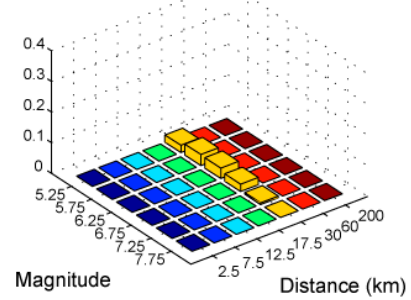

Magnitude

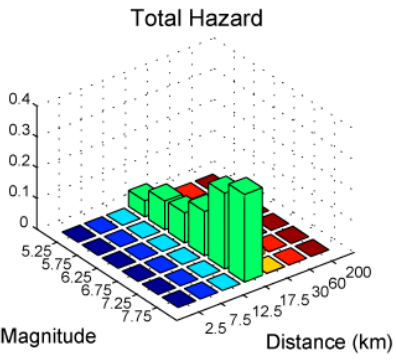

(c)
NS-NP $(63 \%)$
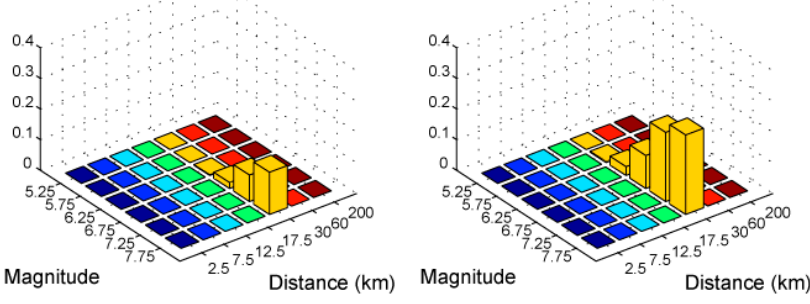

Non-NS ( $0 \%)$

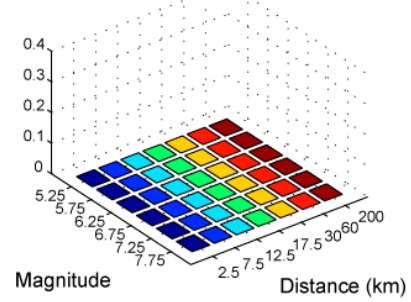

Total Hazard

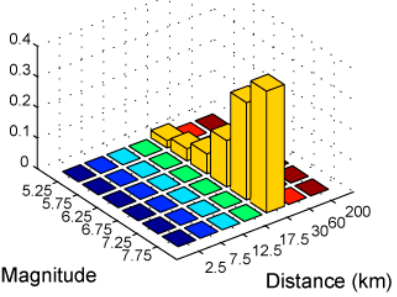

(d)

Figure 14. Distance-magnitude deaggregation plots from the time-domain analyses at a drift of $1 \%$ for sites located at a distance of (a) $6 \mathrm{~km},(\mathbf{b}) 11 \mathrm{~km},(\mathbf{c}) 16 \mathrm{~km}$, and (d) $21 \mathrm{~km}$. Results are shown separately for the total hazard and for the different components of the time-domain analyses. The labels for the components are: NS-P-in-Near-source pulse motions with pulses dominant; NS-P-outnear-source pulse motions with non-dominant pulses; NS-NP—-near-source motions without pulses; and Non-NS-non-near source motions. The value in parenthesis is the total contribution to hazard for each component. 
Another important feature in the graph for near-source motions with dominant pulses (NS-P-in) for $6 \mathrm{~km}$ was that the maximum contribution to demand was coming from low-magnitude earthquakes at smaller distances, as opposed to what was observed in the other deaggregation plots. The reason for this trend was that the lower magnitude earthquakes occurred with higher probabilities, and the pulses from these earthquakes led to a high probability of exceeding drifts of $1 \%$. However, NS-P-out and NS-NP components of small ground motions had lower probabilities of exceeding a drift angle of $1 \%$. Therefore, the total probability that this drift level was exceeded by an NS-P-out and NS-NP component for a small magnitude earthquake was lower than for higher magnitude earthquakes. In the total hazard plot (Figure 14a), the maximum contributor was also the lower magnitude earthquake at short distances. This highlights the importance of lower magnitude earthquakes for structures located in the proximity of a fault.

At a distance of $11 \mathrm{~km}$ (Figure 14b), the NS-P-in contributions were $46 \%$ of the total, lower than the value at $6 \mathrm{~km}$, but still higher than all other components at this distance. As explained earlier, the NS-P-in components of lower magnitude earthquakes contributed significantly to the hazard. However, the higher magnitude earthquakes were contributing more to the total hazard, as the contribution of NS-P-out and the NS-NP components had increased compared to those calculated at a distance of $6 \mathrm{~km}$. As the distance between the source and the fault increased (Figure 14c,d), the contribution of the NS-P-in components to the total hazard decreased. In addition, the contribution of the NS-NP component and higher magnitude earthquakes to the total hazard increased with increasing the distance between the site and the fault.

Figure 15 shows the distance-magnitude deaggregation plots for $1 \%$ drift level from the four different methods, mentioned earlier. At a site to fault distance of $6 \mathrm{~km}$, the traditional, broadband, and enhanced broadband models followed the same trend, that higher magnitude earthquakes contributed more to the total hazard; however, the new PSDA method showed that smaller magnitude earthquakes contributed more to the total hazard (Figure 15a). At a site-to-fault distance of $11 \mathrm{~km}$, all the four models showed that most of the hazard was due to higher magnitude earthquakes (Figure 15b). However, the new PSDA model showed that low-magnitude earthquakes significantly contributed to the total hazard, which differed from the other models. At site-to-fault distances of 16 and $21 \mathrm{~km}$ (Figure 15c,d), all four models showed that the largest contributions to the hazard came from larger magnitude earthquakes since low-magnitude earthquakes occurred at large distances from the bridge, resulting in small drift angles.

Figure 16 shows the pulse amplitude deaggregation plots of the pulse-in component of the new PSDA. The figure illustrates the contribution of various amplitudes and periods of pulses to the NS-P-in component of the hazard. In Figure 16a, which is for a site located at a distance of $6 \mathrm{~km}$ from the fault, it can be seen that the highest contribution was coming from the periods in the range of $0.75 \mathrm{~s}$ and $1.00 \mathrm{~s}$ (centered at $0.875 \mathrm{~s}$ ). This was because a structure was set into resonance whenever the pulse period was equal to the period of structure. The period of the bridge in the current study was $0.8 \mathrm{~s}$. Therefore, a pulse with this period would contribute the most to the NS-P-in component of the hazard. Even though pulses with higher amplitudes induced larger drifts, the probabilities with which they occurred were lower, thus, their total contributions to the hazard were lower. This contribution decreased further as distance to the fault increased (Figure 16b-d, due to the even smaller probabilities of having these higher amplitude pulses in the ground motion). Thus, the contribution of lower amplitude pulses to the hazard increased. 


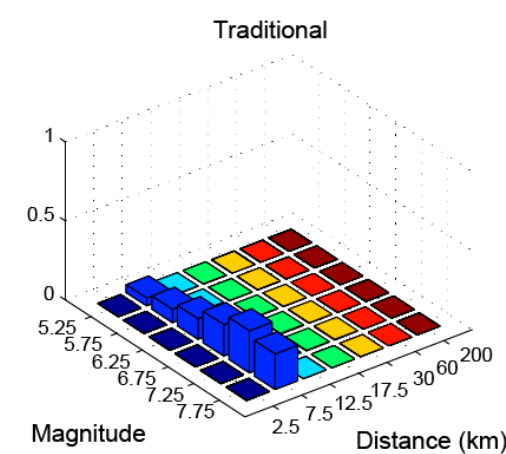

Enhanced Broadband

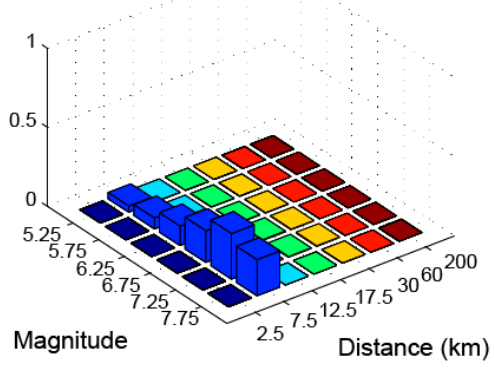

Traditional

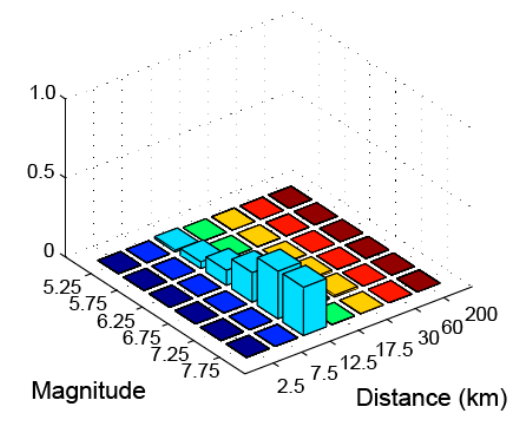

Enhanced Broadband

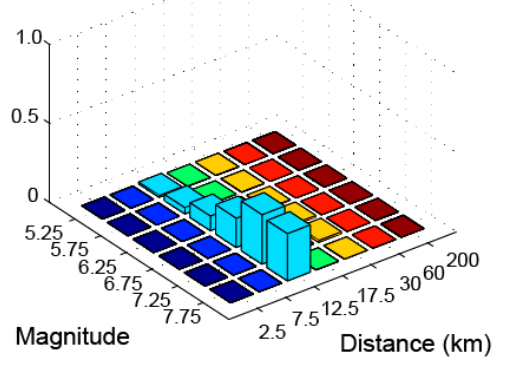

Broadband

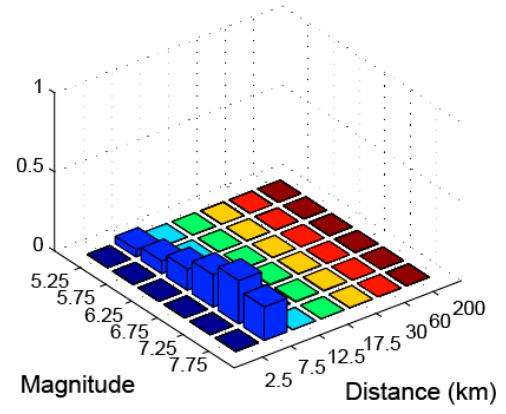

Time Domain

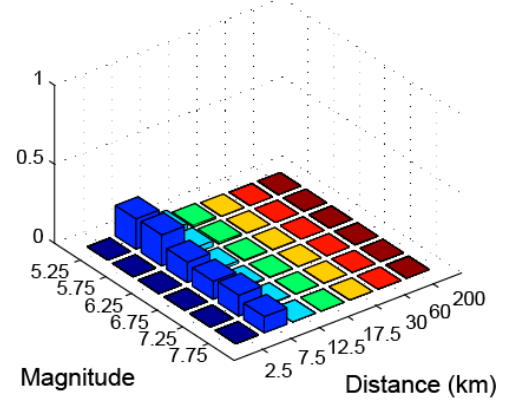

(a)
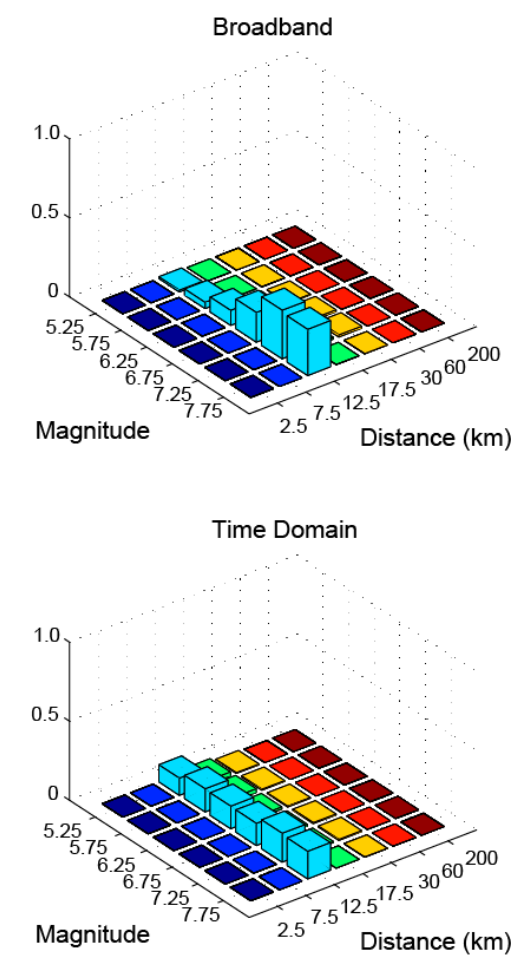

(b)

Figure 15. Cont. 


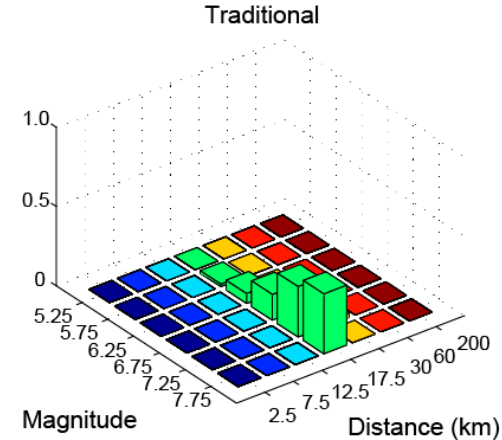

Enhanced Broadband

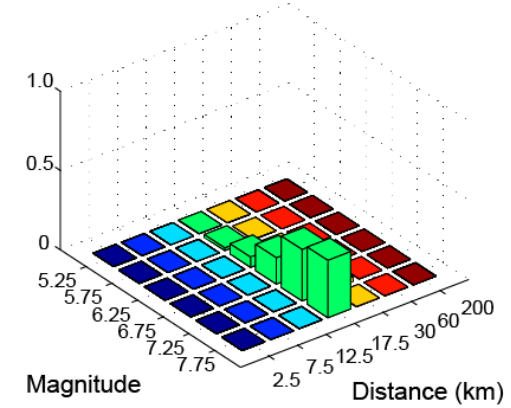

Traditional

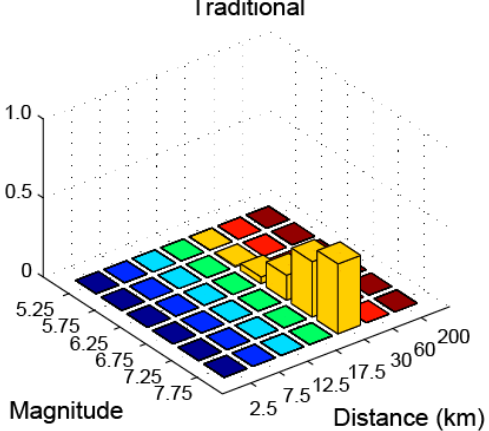

Enhanced Broadband

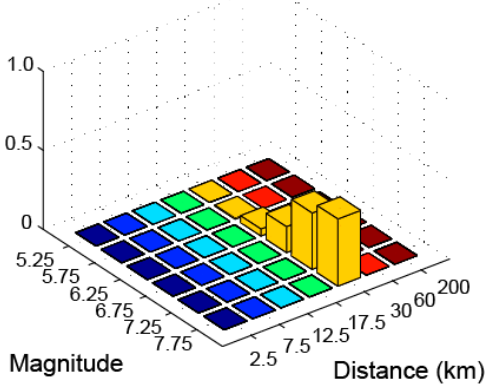

Broadband

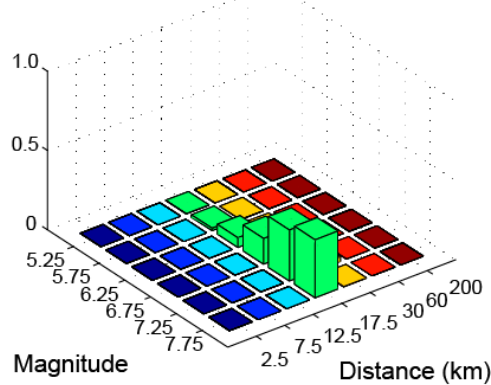

Time Domain

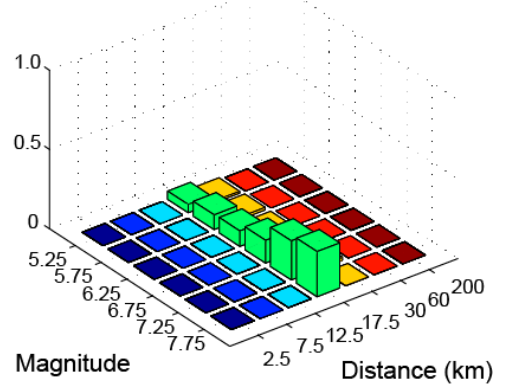

(c)

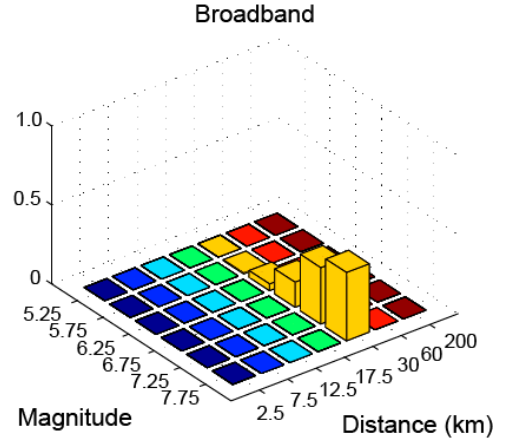

Time Domain

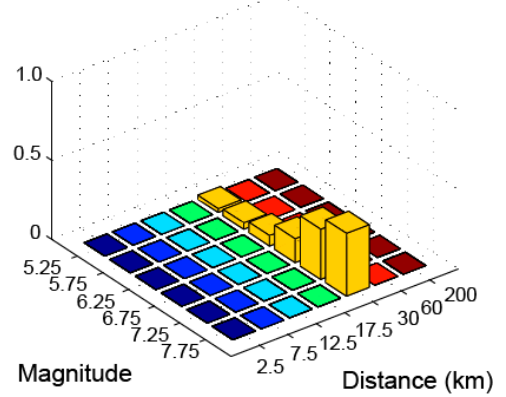

(d)

Figure 15. Magnitude-distance deaggregation at a drift angle of $1 \%$ from the four methods at distances of (a) $6 \mathrm{~km}$, (b) $11 \mathrm{~km},(\mathbf{c}) 16 \mathrm{~km}$ and (d) $21 \mathrm{~km}$ from the fault centerline. 


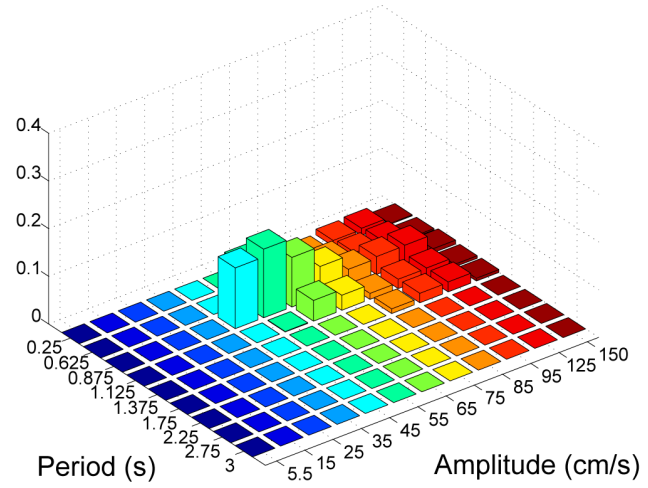

(a)

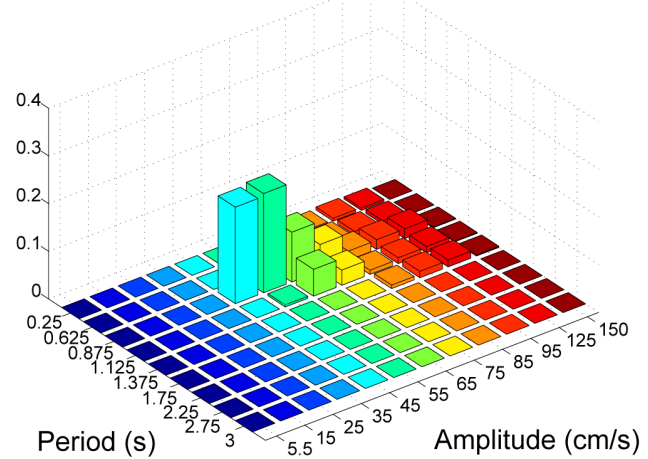

(b)

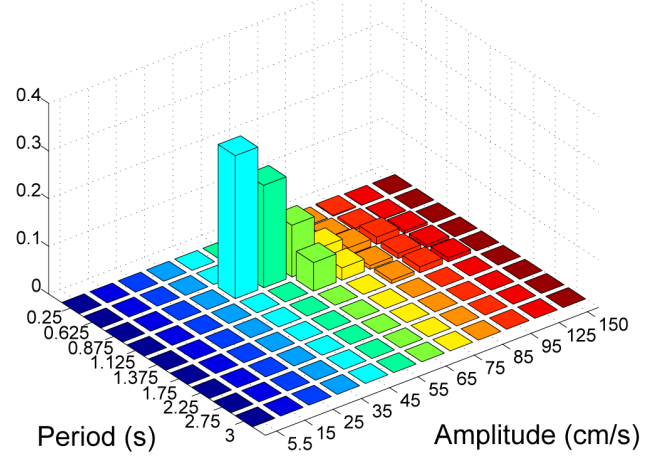

(c)

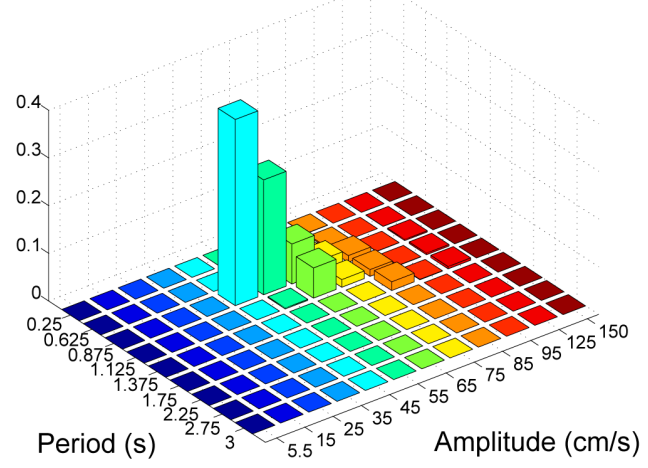

(d)

Figure 16. Period and amplitude deaggregation for a drift angle of $1 \%$ at a distance of (a) $6 \mathrm{~km}$, (b) $11 \mathrm{~km},(\mathbf{c}) 16 \mathrm{~km}$, and (d) $21 \mathrm{~km}$ from the centerline of the fault. 


\section{Conclusions}

This paper presented a methodology for PSDA analysis for a self-centering bridge located in the near-fault zone. An example is presented using a hypothetical fault in which analyses with different degrees of sophistication were conducted. The following conclusions were made:

- Pulse-like ground motions impose a heavy demand on the structure in the near-fault zone. This highlights the importance of properly considering these types of motions when designing bridges in the near-fault region.

- The time-domain approach proposed by Sehhati et al. [16] has the advantage over other methods of PSDA as it uses wavelet pulses to predict structural responses, which allows for the prediction of structural responses for all possible variations of pulse-parameters. This, in turn, permits the capture of potential resonances in the bridge response. Moreover, structural nonlinearities are automatically accounted for in time-domain analyses, whereas in using spectral accelerations, nonlinearities are only captured indirectly. The results of the time-domain analyses, thus, give a better prediction of hazard for sites located in a near-fault region

- The results of the PSDA showed that for a site located very close to the fault (6 $\mathrm{km}$ in this study), small magnitude earthquakes can have significant contributions to structural demand. This observation seems counter-intuitive at first since the results from all methodologies, other than the time-domain approach and conventional wisdom, point to the fact that large magnitude events should contribute most to the hazard. But, if the period of the bridge is closer to the period of the pulses produced by small magnitude events than those produced by large magnitude events, the response of the bridge to small magnitude events may be comparable to the response under large magnitude events. A similar effect is discussed in Somerville [37]. Since the smaller magnitude events occur with greater frequency than larger magnitude events, they can have high contributions to the hazard. The possibility of contribution of small magnitude events to the hazard should be considered while selecting ground motions or while deciding the design scenarios.

- If a return period of 2475 years is considered, the drift values that were obtained from the time-domain PSDA were more than $30 \%$ higher at short distances from the fault than those from methodologies using spectral accelerations modified for near-fault effects. However, this difference reduces to about $15 \%$ at a distance of $11 \mathrm{~km}$. This difference keeps getting smaller as the fault to site distance increases, and beyond distances of $16 \mathrm{~km}$ the difference is less than $5 \%$, even with the high seismicity rate considered here. For more realistic seismicity rates, the difference would be even lower (i.e., for the ground motion prediction models used in this study, the effects of near-fault ground motion were insignificant for sites located more than $16 \mathrm{~km}$ from the fault). At such sites, more traditional methods using spectral accelerations as the intensity measure could be adopted for the hazard calculation instead of the more computationally expensive, proposed time-domain analyses.

While this paper presents a comprehensive analysis of the probabilistic seismic hazard of a bridge designed using unbonded, post-tensioned, concrete-filled FRP tube columns, more case studies need to be investigated to develop a more comprehensive overview of these types of bridges. Parameters such as different span lengths, column heights, boundary conditions, soil-structure interaction, level of post-tension, etc., need to be carefully considered in the proposed case studies.

Author Contributions: The research idea was initiated by M.A.E. and A.R.-M., M.R. carried out the numerical analyses and wrote the paper with close guidance, mentoring, and editing by M.A.E. and A.R.-M.

Funding: This research received no external funding.

Conflicts of Interest: The authors declare no conflict of interest. 


\section{Abbreviations}

$\begin{array}{ll}\text { IM } & \text { Intensity measure } \\ d \lambda & \text { Slope of the mean annual rate of exceedance curve (e.g., the hazard curve) of the IM } \\ \text { EDP } & \text { Engineering demand parameter } \\ P(E D P>x \mid I M) & \text { Conditional probability of exceeding a given EDP level for a given } I M \\ T_{1} & \text { Fundamental period of the structure } \\ T_{p} & \text { Pulse period } \\ A p & \text { Pulse amplitude } \\ S_{a}\left(T_{1}\right) & \text { Fundamental period of the bridge } \\ A & \text { A constant proportional to the amplitude of the wavelet } \\ f_{p} & \text { Prevailing frequency of the signal } \\ v & \text { Phase angle } \\ \gamma & \text { Defines the oscillatory character of the signal } \\ t_{0} & \text { Time of the envelope's peak }\end{array}$

\section{References}

1. SEAOC. Performance Based Seismic Engineering for Buildings (Vision 2000); Structural Engineers Association of California: Sacramento, CA, USA, 1995.

2. Somerville, P.G.; Smith, N.F.; Graves, R.; Abrahamson, N.A. Modification of Empirical Strong Ground Motion Attenuation Relations to Include the Amplitude and Duration Effects of Rupture Directivity. Seismol. Res. Lett. 1997, 68, 199-222. [CrossRef]

3. Bertero, V.V.; Mahin, S.A.; Herrera, R.A. Aseismic design implications of near-fault San Fernando earthquake records. Earthq. Eng. Struct. Dyn. 1978, 6, 31-42. [CrossRef]

4. Anderson, J.C.; Bertero, V.V. Uncertainties in establishing design earthquakes. J. Struct. Eng. 1987, 113, 1709-1724. [CrossRef]

5. Hall, J.F.; Heaton, T.H.; Halling, M.W.; Wald, D.J. Near-source ground motion and its effects on flexible buildings. Earthq. Spectra 1995, 11, 569-605. [CrossRef]

6. Iwan, W.; Huang, C.-T.; Guyader, A.C. Evaluation of the Effects of Near-Source Ground Motions; Report Developed for the PG\&E/PEER Program, CalTech: Pasadena, CA, USA, 1998.

7. Alavi, B.; Krawinkler, H. Effects of Near-Fault Ground Motions on Frame Structures; Dept. of Civil Eng., Stanford University: Stanford, CA, USA, 2001.

8. Menun, C.; Fu, Q. An analytical model for near-fault ground motions and the response of SDOF systems. In Proceedings of the 7th U.S. National Conference on Earthquake Engineering, Boston, MA, USA, 21-25 July 2002; p. 10.

9. Makris, N.; Black, C.J. Dimensional analysis of bilinear oscillators under pulse-type excitations. J. Eng. Mech. 2004, 130, 1019-1031. [CrossRef]

10. Mavroeidis, G.P.; Dong, G.; Papageorgiou, A.S. Near-Fault ground motions, and the response of elastic and inelastic Single-Degree-of-Freedom (SDOF) systems. Earthq. Eng. Struct. Dyn. 2004, 33, 1023-1049. [CrossRef]

11. Akkar, S.; Yazgan, U.; Gulkan, P. Drift estimates in frame buildings subjected to Near-Fault ground motions. J. Struct. Eng. 2005, 131, 1014-1024. [CrossRef]

12. Luco, N.; Cornell, C.A. Structure-Specific Scalar Intensity Measures for Near-Source and Ordinary Earthquake Ground Motions. Earthq. Spectra 2007, 23, 357-392. [CrossRef]

13. Hall, J.F. Seismic response of steel frame buildings to near-source ground motions. Earthq. Eng. Struct. Dyn. 1998, 27, 1445-1464. [CrossRef]

14. Zhang, Y.; Iwan, W. Active interaction control of tall buildings subjected to near-field ground motions. J. Struct. Eng. 2002, 128, 69-79. [CrossRef]

15. Spudich, P.; Chiou, B. Directivity in NGA earthquake ground motions: Analysis using isochrone theory. Earthq. Spectra 2008, 24, 279-298. [CrossRef]

16. Sehhati, R.; Rodriguez-Marek, A.; ElGawady, M.; Cofer, W.F. Response of Multi-Story Structures to Near-Fault Ground Motions and Equivalent Pulses. Eng. Struct. 2011, 33, 767-779. [CrossRef] 
17. Priestley, N.; Sritharan, S.; Conley, J.; Pampanin, S. Preliminary results and conclusions from the PRESSS five-story precast concrete test building. PCI J. 1999, 44, 42-76. [CrossRef]

18. ElGawady, M.A.; Sha'lan, A. Seismic behavior of self-centering precast segmental bridge bents. J. Bridge Eng. 2011, 16, 328-339. [CrossRef]

19. ElGawady, M.A.; Booker, A.J.; Dawood, H. Seismic behavior of posttensioned concrete-filled fiber tubes. J. Compos. Const. 2010, 14, 616-628. [CrossRef]

20. Moustafa, A.; ElGawady, M.A. Shaking table testing of segmental hollow-core FRP-concrete-steel bridge columns. J. Bridge Eng. 2018, 23, 04018020. [CrossRef]

21. Ichikawa, S.; Matsuzaki, H.; Moustafa, A.; ElGawady, M.A.; Kawashima, K. Seismic-resistant bridge columns with ultrahigh-performance concrete segments. J. Bridge Eng. 2016, 21, 04016049. [CrossRef]

22. Marriott, D.; Pampanin, S.; Palermo, A. Quasi-static and pseudo-dynamic testing of unbonded post-tensioned rocking bridge piers with external replaceable dissipaters. Earthq. Eng. Struct. Dyn. 2009, 38, 331-354. [CrossRef]

23. Abdelkarim, O.; ElGawady, M.A.; Anumolu, S.; Gheni, A.; Sanders, G. Behavior of hollow-core FRP-concrete-steel columns under static cyclic flexural loading. J. Struct. Eng. 2018, 144, 04017188. [CrossRef]

24. Abdelkarim, O.; ElGawady, M.A.; Gheni, A.; Anumolu, S.; Abdulazeez, M. Seismic performance of innovative hollow-core FRP-concrete-steel bridge columns. J. Bridge Eng. 2017, 22, 04016120. [CrossRef]

25. ATC/MCEER Joint Venture; Comprehensive Specification for the Seismic Design of Bridges; NCHRP Report; National Academy Press: Washington, DC, USA, 2002.

26. ElGawady, M.A.; Dawood, H. Analysis of segmental piers consisted of concrete filled FRP tubes. Eng. Struct. 2012, 38, 142-152. [CrossRef]

27. Dawood, H.; ElGawady, M.A.; Hewes, J. Factors affecting the seismic behavior of segmental precast bridge columns. Front. Struct. Civ. Eng. J. 2014, 8, 388-398. [CrossRef]

28. Dawood, H.; ElGawady, M.A. Performance-based seismic design of unbonded precast post-tensioned concrete filled GFRP tube piers. Compos. Part B Eng. 2013, 44, 357-367. [CrossRef]

29. Zhu, Z.; Mirmiran, A.; Saiidii, M.S. Seismic Performance of Reinforced Concrete Bridge Substructure Encased in Fiber Composites. Transp. Res. Rec. 2006, 1976, 197-206. [CrossRef]

30. Hewes, J.T.; Priestley, N. Seismic Design and Performance of Precast Concrete Segmental Bridge Columns; Report No. SSRP-2001/25; Univ. of California at San Diego: San Diego, CA, USA, 2002.

31. Samaan, M.; Mirmiran, A.; Shahawy, M. Model of concrete confined by fiber composite. J. Struct. Eng. 1998, 124, 1025-1031. [CrossRef]

32. Abrahamson, N.A.; Silva, W. NGA Ground Motion Relations for the Geometric Mean Horizontal Component of Peak and Spectral Ground Motion Parameters; Pacific Earthquake Engineering Research Center College of Engineering, University of California: Berkeley, CA, USA, 2007.

33. Abrahamson, N.A. Effects of Rupture Directivity on Probabilistic Seismic Hazard Analysis. In Proceedings of the Sixth International Conference on Seismic Zonation, Palm Springs, CA, USA, 12-15 November 2000.

34. Iervolino, I.; Cornell, C.A. Probability of occurence of velocity pulses in near-source ground motions. Bull. Seismol. Soc. Am. 2008, 98, 2262-2277. [CrossRef]

35. Bray, J.D.; Rodriguez-Marek, A. Characterization of forward-directivity ground motions in the near-fault region. Soil Dyn. Earthq. Eng. 2004, 24, 815-828. [CrossRef]

36. Baker, J. Quantitative classification of near-fault ground motions using wavelet analysis. Bull. Seismol. Soc. Am. 2007, 97, 1486-1501. [CrossRef]

37. Somerville, P.G. Magnitude scaling of the near fault rupture directivity pulse. Phys. Earth Planet. Inter. 2003, 137, 201-212. [CrossRef]

(C) 2019 by the authors. Licensee MDPI, Basel, Switzerland. This article is an open access article distributed under the terms and conditions of the Creative Commons Attribution (CC BY) license (http:/ / creativecommons.org/licenses/by/4.0/). 